\title{
Integrando la sexualidad en la planificación familiar: La experiencia de tres proyectos de VIH/ETS en América Latina y el Caribe
}

Julie Becker

Elizabeth Leitman

Mahmoud F. Fathalla

Follow this and additional works at: https://knowledgecommons.popcouncil.org/departments_sbsr-pgy

Part of the Community Health and Preventive Medicine Commons, Family, Life Course, and Society Commons, Gender and Sexuality Commons, International Public Health Commons, Public Health Education and Promotion Commons, and the Women's Health Commons How does access to this work benefit you? Let us know!

\section{Recommended Citation}

Becker, Julie, Elizabeth Leitman, and Mahmoud F. Fathalla. 1997. "Integrando la sexualidad en la planificación familiar: La experiencia de tres proyectos de VIH/ETS en América Latina y el Caribe," Quality/ Calidad/Qualité no. 8. New York: Population Council. 
Quality/Calidad/Qualité es una publicatión del Population Council que documenta ejemplos de programas de planificación familiar y salud reproductiva que proveen un nivel de calidad de atención estraordinariamente alto. Está serie forma parte del Programa Robert H. Ebert sobre Temas Críticos en Salud Reproductiva, un programa del Council que busca mejorar y ampliar el alcance y la calidad de la atención en salud reproductiva a través de iniciativas científicas y prácticas. La base filosófica del programa, y de esta serie, es el clerecho funclamental cle las mujeres y sus parejas al trato respetuoso, la información, las opciones y el seguimiento por parte de los proveedores de atención en salud reproductiva. Los folletos reflejan uno de los cuatro impulsos principales del programa: aumentar la caliclad de los programas de planificación familiar.

Los proyectos que se incluyen en Quality/Calidad/Qualité son seleccionados por un Comité Asesor de individuos que representan una amplia gama de experiencia en el ámbito de la salud reproductiva, y que están comprometidos a mejorar la calidad de atención. Los proyectos se eligen por estar logrando importantes avances en por los menos uno de los siguientes aspectos: ampliar la gama de opciones cle métodos y technologías anticonceptivas disponsibles; proporcionar la información que las clientes necesitan para hacer elecciónes informadas y para controlar mejor su salud reproductiva; mejorar la calidad del trato entre proveedor y cliente, promoviendo la continuación del contacto entre ambos; iniciar proyectos innovadores para aumentar la capacidad administrativa y ampliar el nivel de capacitatión de los proveedores de servicios a todo nivel; extender la gama de servicios en información más allá de los que convencionalmente se define como "planificación familiar"; y alcanzar, con los servicios de salud reproductiva, a grupos que generalmente no los reciben.

Ninguno de los proyectos incluídos en la serie se está presentando como un modelo para la replicación. Se ofrecen más bien como un ejemplo singularmente creativo de valores, objectivos y aplicación de ideas. Estas son "experiencias de aprendizaje" que ilustran la necesidad de mantener una actitud autocrítica para anticipar las necesidades de las clientes y para encontrar medios económicos de satisfacerlas. Esta actitud reflexiva se manifiesta en la voluntad de responder a los cambios en las necesidades de las clientes y en las transformaciónes econónicos y sociales en general. Esperamos que la documentación de las decisiones críticas que estos programas han tenido que hacer ayudará a reforzar en términos prácticos, la evidencia cle que la satisfacción del individuo con los servicios de salud reproductiva está fuertemente ligada al logro de objectivos más amplios en salud y población.

La publicación de esta edición de Quality/Calidad/Qualité en español hat sido posible por el apoyo brinclado por la Fundación Ford, the John D. and Catherine T. MacArthur Foundation y Swedish International Development Cooperation Agency (SIDA).
Las declaraciones y opiniones expresadas en esta publicación son la responsabiliclad exclusiva del autor y no de ninguna organización que provea apoyo para Quality/Calidad/Qualité.

La edición en inglés se publicó en 1997

Edición en español No. 8, 1997. ISSN 0-87834-057-2

Copyright $($ The Population Council 1997 


\title{
Integrando la sexualidad en la planificación familiar: La experiencia de tres proyectos de VIH/ETS en América Latina y el Caribe
}

\author{
por Julie Becker y Elizabeth Leitman \\ Introducción de Mahmoud F. Fathalla
}

\section{Introducción}

Este informe sobre la integración de la sexualidad en la planificación familiar me hizo acordar de un interesante encuentro que tuve en la India hace unos años. Durante una reunión científica sobre planificación familiar en la que participaba, se me acercaron los miembros de un grupo que promovía un "novedoso" método de planificación familiar. Dichos promotores aseguraban_correctamente-que este método era $100 \%$ eficaz, que no tenía efectos secundarios, que servía tanto para hombres como para mujeres, y que ofrecía protección total contra las enfermedades de transmisión sexual. El método era apropiado para cualquier tipo de usuario y carecía de contraindicación alguna. Es más, en aquel momento, este método anticonceptivo costaba sólo 35 rupias (aproximadamente un dólar estadounidense).

Los promotores estaban desilusionados porque a pesar de todas estas ventajas, no lograban vender el método. Lo estaban comercializando bajo el nombre "El gozo de la abstinencia". El producto recomendaba la supresión total del impulso sexual, y las 35 rupias compraban un librito que enseñaba ejercicios de yoga para ayudar con el cumplimiento del método. Evidentemente, cuando uno pasa mucho tiempo en posición de cabeza, jresulta difícil pensar en los deseos asociados con el otro extremo del cuerpo! E] movimiento de planificación familiar no alcanzó a recomendar "El gozo de la abstinencia", pero durante muchos años sí se negó a reconocer que el sexo tiene mucho que ver con la planificación familiar. De hecho, la planificación familiar siempre tiene que ver con la sexualidad. Su propósito fundamental es permitir que los hombres y las mujeres disfruten de relaciones sexuales mutuamente satisfactorias sin temer el embarazo no deseado.

La disociación del sexo y la reproducción es un hecho que ocurre a propósito en la evolución de la especie humana, a pesar de lo que algunos teólogos prefieren creer. En la evolución de homo sapiens, la relación temporal entre el sexo y la reproducción ha quedado completamente separada. En otras especies de mamíferos, el macho sólo siente atracción por la hembra si ésta está ovulando y lista para concebir. Entre nuestros parientes los primates, la hembra siempre anuncia el hecho de que está ovulando: sus órganos sexuales externos cambian visiblemente de tamaño y color, provocando el deseo del macho. Fuera de este breve ciclo de fecundidad, tanto el macho como la hembra carecen de interés sexual en el género opuesto.

Pero la receptividad y atracción sexual de la mujer en la especie humana ha sido completamente emancipada del control hormonal. Por medio de la evolución, la mujer ha logrado esconder por completo toda señal externa de la ovulación. Es evidente que la naturaleza quiso que el acto sexual humano existiera por razones otras que el utilitario proceso de reproducción. Como demuestra la tendencia voluntaria hacia familias de menor tamaño, el sexo se está convirtiendo cada vez más en un aspecto de nuestro bienestar psicosocial y cada vez menos en una herramienta para la reproducción.

Lamentablemente, fue necesaria la aparición de la pandemia del Virus de Inmunodeficiencia Humano (VIH) para que el movimiento de planificación familiar se despertara a la realidad de la vida sexual de la gente. Ha sido un despertar paulatino, porque resulta difícil cambiar la perspectiva de un movimiento que históricamente ha sido animado por consideraciones principalmente demográficas. Incluso es posible que algunos-esperemos que pocos — vean en el VIH y las enfermedades de transmisión sexual una manera más de ayudar a disminuir el problema mundial de la población. Visto de este modo, es posible decir que los dos programas de oclusión tubal femenina de mayor "éxito" son las infecciones de chlamydia 
trachomatis y neisseria gonorrea. Estas enfermedades no se molestan en conseguir el consentimiento de la mujer-jlas víctimas quedan esterilizadas sin saberlo!

Pero el movimiento de planificación familiar necesitaba algo más que un reconocimiento de la realidad de la vida sexual de la gente motivado por la urgencia de la epidemia mundial en enfermedades de transmisión sexual. En efecto, lo que el movimiento necesitaba era preocuparse más por la gente y menos por el concepto de la "población”. Era hora de cambiar el enfoque en cifras y censos por uno que midiera el valor de las personas, de preocuparse menos por objetivos demográficos y más por las necesidades del individuo. La planificación familiar necesitaba una perspectiva suficientemente amplia como para abarcar la totalidad de las necesidades sexuales y reproductivas de cada persona.

Inicialmente muchos profesionales de la planificación familiar reaccionaron en contra de este cambio. Muchos creían que los servicios de planificación familiar no tienen la capacidad para añadir nuevas tareas, y que dichas tareas socavarían los limitados recursos que en la actualidad se destinan a la planificación familiar. Pero hoy en día se está formando un consenso en torno a la convicción de que tanto la salud sexual como la reproductiva deben atenderse en forma integral_como un sólo "paquete"—y que dicho enfoque debería regir tanto en los niveles de formación de políticas, gerencia y administración como en el nivel de entrega de servicios. El Diccionario Oxford define la palabra "integrar" del siguiente modo: "completar (una cosa imperfecta) al sumarle partes; combinar (partes) par"a formar algo entero". Por ende, integrar no debe confundirse con añadir, agregar o simplemente "juntar" cosas. Porque cuando varios servicios se "juntan" de forma improvisada e incoherente, el resultado no es integración. La integración sólo ocurre cuando dichos servicios son combinados en base a una estrategia que busca producir un "paquete" más completo, en el cual el cliente funciona como centro y enfoque de la atención.

La salud sexual y reproductiva tiene que ver con las relaciones entre hombres y mujeres, aunque algunos de los aspectos del tema preocupen más a la mujer. Las mujeres tienen menos poder cuando se trata de negociar relaciones sexuales, y son ellas las que quedan embarazadas. Por definición, las enfermedades de transmisión sexual (ETS) afectan tanto a mujeres como hombres, pero las mujeres cargan desproporcionadamente con las consecuencias de estas enfermedades. Un reciente estuclio del Banco Mundial clasificó a las ETS como la segunda causa general de enfermedad (después de las causas relacionadas a la maternidad) entre mujeres de 15 a 47 años de edad en los países en vías de desarrollo. Entre los hombres de la misma edad, las ETS no figuraban si quiera entre las primeras diez causas de la enfermedad. (1)

Una mezcla de razones biológicas y sociales hace que las mujeres tengan una mayor probabilidad de quedar infectadas con ETS, una menor probabilidad de buscar atención médica, y que resulten más difíciles de diagnosticar. Las mujeres también sufren consecuencias médicas más graves cuando contraen una ETS, además de ser más susceptibles a la discriminación social asociada con estas enfermedades. E] método anticonceptivo que ofrece la mejor protección contra las ETS-el condón-es controlado por el hombre; por razones obvias, las mujeres no pueden "usar" un condón. Todavía no existe un método que la mujer pueda usar sin la cooperación de su pareja, que proporcione protección eficaz contra lia enfermedad. Sin embargo, el hecho de que la salud sexual tiene consecuencias más serias para las mujeres no significa que a los hombres se los puede dejar afuera. Los hombres tienen sus propias necesidades de salud sexual, y su salud sexual está ligada a la de las mujeres. Los hombres pueden jugar un papel positivo en la promoción de la salud sexual y reproductiva de sus parejas. Pero lamentablemente, muchos hombres ignoran la naturaleza de su papel en la salud de la mujer y tienen un efecto perjudicial en la misma.

Cambiar nunca es fácil, especialmente cuando lo que se trata de cambiar a la gente. Es mucho más fácil impartir nuevos conocimientos a los proveedores de servicios o ayudarles a conseguir nuevas capacidades técnicas. El gran desafío consiste en cambiar la actitud de los proveedores hacia la sexualidad, cambio que debe empezar con una aclaración o reexaminación de sus propios valores y comportamientos sexuales. Cambiar actitudes es lo que más importa, porque las actitudes nunca son una simple suma de conocimientos y capacidades. En realidad existe un "efecto de multiplicación": si la actitud hacia el riesgo y la expresión sexual es equivalente a un cero, el resultado de impartir cualquier cantidad de conocimientos y capacidades también suele ser cero.

El cambio requiere liderazgo, innovación y una voluntad de tomar riesgos_riesgos como los que tres asociaciones de planificación familiar en América Latina y el Caribe tomaron cuando decidieron introducir la sexualidad en la planificación familiar. Al cabo de toclo, resultó que habían introducido la planificación familiar en la sexualidad. Hicieron bien, y su experiencia merece nuestra atención. 


\section{Antecedentes}

Escena 1, una clínica de planificación familiar (1993): Un lluvioso miércoles por la mañana. Patricia, una vendedora ambulante, llega a la clínica urbana buscando un método de planificación familiar por primera vez. Después de una breve espera, una consejera la recibe con una cálicla bienvenida, repite su nombre, y la conduce a una sala privada donde se sientan para la consulta.

La consejera le hace una serie de preguntas a Patricia y escucha atentamente a las respuestas. Patricia dice que jamás ha utilizado planificación familiar, pero que una amiga le ha dicho que la píldora es un buen método. Luego de repetir lo que Patricia ha dicho para asegurarse de que la comprende, la consejera le pregunta si sabe algo de otros métodos de planificación familiar.

Cuando Patricia indica que sabe muy poco, la consejera le describe cada método en detalle, explicando el modo de utilización de cada uno, cómo insertar un diafragma, qué hacer si se le olvida tomar una píldora, qué hacer si se le olvidan dos, etc. Cuando describe un condón, la consejera le muestra un pequeño paquete plástico a Patricia. Le dice que es bueno usar condones cuando se le olvida la píldora, y que también es importante usarlos durante un tiempo después de empezar a tomar la píldora, para asegurase de que haya tomado efecto. Luego la consejera le muestra los distintos tipos de píldoras disponibles y discute las opciones en cuanto al precio. Patricia se va de la clínica con un suministro de tres meses de píldoras.

$\circ 00 \% 0000$

Escena 2, la misma clínica (1996): Un lluvioso miércoles por la mañana. Patricia, una vendedora ambulante, llega a la clínica urbana buscando un método de planificación familiar por primera vez. Después de una breve espera, una consejera la recibe con una cálida bienvenida, repite su nombre, y la conduce a una sala privada donde se sientan para la consulta.

La consejera le hace una serie de preguntas a Patricia y escucha atentamente a las respuestas. Patricia dice que jamás ha utilizado un método de planificación familiar, pero que su cuñada usa la píldora y que piensa que le gustaría hacer lo mismo. La consejera dedica varios minutos a explorar la vida y situación individual de Patricia, mediante preguntas al respecto. Hablan de la familia de Patricia, su pareja actual, parejas previas, y su nivel de satisfacción con su vida sexual. Patricia menciona que su marido viaja a menudo por el trabajo.
La consejera pregunta si Patricia cree que su marido mantiene relaciones con otras mujeres durante sus viajes, y Patricia responde que supone que sí. Las dos discuten el hecho de que esto puede exponer a Patricia al Virus de Inmunodeficiencia Adquirido (VIH) u otras enfermedades de transmisión sexual (ETS), y repasan lo que Patricia sabe sobre estos temas. La consejera corrige algunos conceptos erróneos y explica en detalle cuáles actividades sexuales son sanas y cuáles riesgosas.

Luego la consejera describe los beneficios asociados con el condón, utilizando un modelo de pene para demostrar el uso correcto y explicando que los condones ofrecen una protección muy eficaz contra el embarazo, el VIH y las ETS cuando se los utiliza correcta y consistentemente. La consejera también recomienda algunas maneras de hacer que el condón sea más agradable para el hombre, como ser que la mujer se lo coloque mientras le acaricia el pene.

La consejera le pregunta a Patricia si alguna vez ha tenido una ETS o cualquier otra infección, y si Patricia ha hablado sobre el VIH alguna vez con su marido-si es que llegan a conversar sobre el sexo. Patricia confiesa que no han conversado sobre esos temas, y que quisiera poder hacerlo. Luego las dos discuten distintas estrategias para introducir el tema de un modo que no sea amenazante para el marido de Patricia.

Finalmente, la consejera hace un breve repaso de todos los métodos de planificación familiar disponibles, enfatizando el hecho de que es necesario usar el condón con todos los otros métodos para lograr protección contra el VIH y las ETS. Patricia elige la píldora y la consejera le explica en detalle cómo usar este método. Patricia se va de la clínica con un suministro de píldoras para tres meses y un paquete de condones gratis para probar.

00000000

Estas descripciones de "típicas" sesiones de asesoramiento en planificación familiar representan un compuesto de sesiones que tuvieron lugar antes de 1993 y después de 1996. Durante esos años tres asociaciones de planificación familiar (APF) afiliadas con la International Planned Parenthood Federation/Western Hemisphere Region (IPPF/WHR) implementaron un proyecto para integrar la prevención del VIH y las ETS en los servicios y programas de planificación familiar.

Hacia 1996, la típica sesión de consejería en estas APF mostraba los efectos de una profunda evolución. Lo que antes había sido un encuentro básicamente informativo ahora era un verdadero intercambio entre el cliente y la consejera, en el 
cual se exploraban las necesidades del cliente en el contexto de la salud sexual y reproductiva. Esta edición de Quality/Calidad/Qualité relata cómo el personal de BEMFAM en Brasil, ASHONPLAFA en Honduras y FAMPLAN en Jamaica logró la transición a un estilo de provisión de servicios de planificación familiar más centrado en el cliente y más explícito en lo sexual. También se presentan testimonios de lo que esta transición significó para estos proveedores y para sus clientes.

\section{Evolución de los programas y las actitudes de las asociaciones de planificación familiar en el hemisferio oeste}

A lo largo de la historia de la planificación familiar; la mayoría de los programas se han concentrado casi exclusivamente en la entrega de servicios anticonceptivos. Al principio estos servicios sólo se ofrecían en clínicas, pero más tarde la oferta se extendió a sistemas comunitarios de distribución y programas de mercadotecnia social. Pero incluso cuando operaban afuera de las clínicas, estos servicios se atenían a una tradición médica que no trataba de atender a las necesidades de salud reproductiva y sexual del cliente y no pretendía indagar en cuestiones de sexualidad. Los proveedores de servicios de planificación familiar muchas veces no consideraban la realidad de la vida sexual de sus clientes o el contexto social y cultural en el que ocurre la actividad sexual. Motivados por metas cuantitativas para controlar el crecimiento de la población, muchos programas promovían méto- dos "más eficaces", de largo plazo, como los dispositivos intrauterinos (DIU) y la esterilización. En estas circunstancias casi nunca se mencionaban los condones, y mucho menos se los recomendaba como método prioritario.

En años recientes, el movimiento de planificación familiar ha empezado a mostrar una mayor conciencia sobre la temática del género y la importancia de la calidad de la atención. Últimamente este enfoque se ha ampliado para incluir la salud sexual y reproductiva. La Conferencia Internacional sobre Población y Desarrollo que tuvo lugar en el Cairo en 1994 reafirmó la iclea de que la salud sexual y reproductiva va más allá de la provisión de servicios de planificacción familiar y debe incluir servicios como la prevención y el tratamiento de infecciones del sistema reproductivo y las ETS, incluso el VIH. Pero el desafío de implementar esta visión en los programas de planificación familiar existentes ha resultado difícil para los gerentes y el personal de dichos programas.

En los primeros años de la epidemia del SIDA, muy pocas de las asociaciones de planificación familiar del hemisferio oeste querían involucrarse con el tema. Muchos pensaban que el SIDA sólo afectaba a grupos marginados, y no a las mujeres casadas o en relaciones estables que supuestamente formaban el principal sector de clientes para la planificación familiar. Poco a poco quedó claro que la epidemia estaba afectando a todas las mujeres-incluso aquellas "protegidas" por relaciones monógamas o estables. Sin embargo, las APF temían que la entrega de servicios relacionados al VIH y las ETS podría inquietar $u$

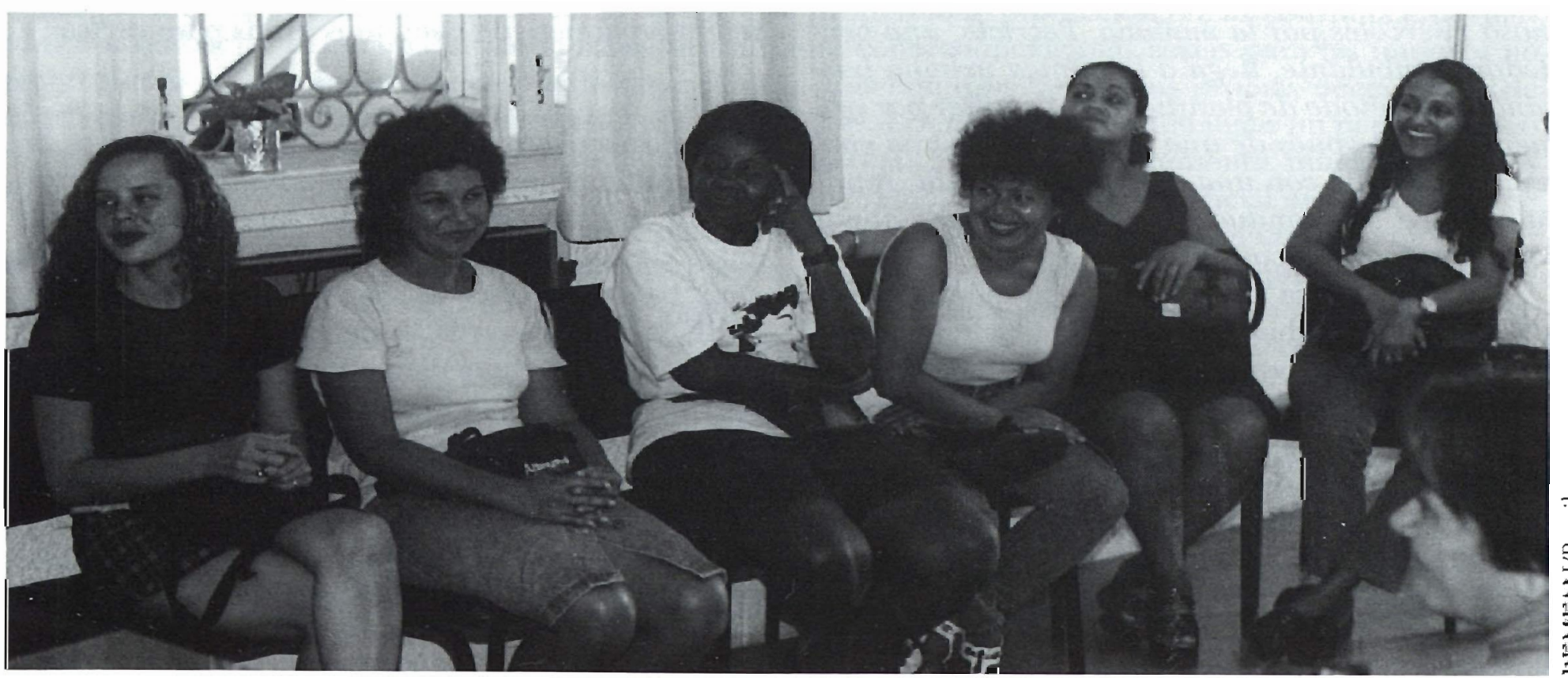


ofender a los clientes de la planificación familiar, y que por ende dichos servicios obrarían en contra de la función de las APF. También preocupaba el costo de integrar los servicios para el VIH y las ETS con los de planificación familiar. Muchos pensaban que este costo sería demasiado alto, lo cual podría perjudicar los esfuerzos de las APF por alcanzar autosuficiencia económica. A fines de la década de los 80 y a principios de los 90 , las APF que intentaban ofrecer servicios de VIH/ETS generalmente se enfocaban en los "grupos de alto riesgo", como ser los hombres homosexuales, las prostitutas, o poblaciones generales fuera de las que típicamente asistían as las clínicas de planificación familiar. Muy pocas asociaciones entablaron los temas del VIH y las ETS con sus propios clientes u ofrecieron servicios para dichas enfermedades en sus propias instalaciones.

Al principio de la clécada de los 80 , las actividacles de prevención del VIH apoyadas por la IPPF/WHR en la región tenían dos propósitos generales. El primero era reducir el estigma social que el SIDA solía provocar en esos años. El segundo objetivo era facilitar el reconocimiento, por parte de las APF, de que la epidemia del SIDA amenazaba cada vez más a las mujeres en relaciones estables-cs decir, a los clientes de las APF. Aunque estos esfuerzos fueron de pequeña escala y tuvieron un impacto limitado, de todos modos abrieron paso para un tratamiento más amplio e integrado del tema.

En 1992, la U.S. Agency for International Development (USAID) (2) proporcionó fondos para que la IPPF/WHR desarrollara un proyecto piloto de integración de prevención del VIH y las ETS en los programas y servicios de planificación familiar de tres APF en América Latina y el Caribe: BEMFAM/Brasil, ASHONPLAFA/Honduras, y FAMPLAN/Jamaica. Estos nuevos recursos crearon una oportunidad para desarrollar programas integrados de mayor escala dentro de estas APF.

$\mathrm{Al}$ comenzar el proyecto existía muy poca experiencia sobre la integración de la prevención del VIII y las ETS con la planificación familiar, por lo cual la IPPF/WHR y las tres APF tuvieron que definir estrategias sin la ventaja de modelos preexistentes. Sin embargo esto resultó ser positivo, dado que permitió que cada APF elaborara una estrategia particular en base a sus propias estructuras de servicio, sus propias percepciones de las necesidades de los clientes, y los intereses y conceptos particulares del personal. A medida que estos programas maduran en el futuro, se espera que otras APF en la región y en otras partes del mundo puedan aprovechar lo que estas tres han aprendido. Porque a pesar de las diferencias culturales, linguísticas y programáticas entre las tres $\mathrm{APF}$, muchos de los problemas que tuvieron que resolver fueron muy parecidos.

\section{INICIANDO EL PROCESO DE CAMBIO}

\section{Consejería y educación antes del proyecto}

Ya para 1993, la gran parte del personal de atención en las APF de América Latina y el Caribe poseía buenos niveles de educación y una buena capacidad para proveer consejería al cliente. Es decir, el personal era capaz de escuchar atentamente, demostrar empatía y reflejar fielmente las necesidades expresadas por cada cliente. Sin embargo, muchos de estos trabajadores utilizaban dichas capacidades en un marco demasiado estrecho, prestándole poca atención a temas más delicados como ser las prácticas sexuales y las relaciones personales. Aunque se practicaban algunas actividades participatorias de extensión o educación en grupos, la "consejería" individual típico consistía en la transmisión unidireccional de información desde la "consejera" hacia el cliente. Muchos empleados en las APF no se sentían cómodos discutiendo temas relacionados al VIH, las ETS o la sexualidad. Si llegaban a promover el condón, sólo lo hacían como método de respaldo, en vez de ofrecerlo como una opción válida para planificación familiar y prevención del VIH y las ETS.

Cuando comenzó el proyecto, casi todos los trabajadores en las APF eran concientes de la existencia del SIDA, pero pocos conocían la enfermedad en cletalle, y menos todavía entendían la conexión entre el VIH, las ETS, la planificación familiar y la sexualidad. Muchos tenían ideas equivocadas sobre las vías de transmisión del VIH, y pocos entendían que se pueden tener algunas ETS sin exhibir síntomas de la enfermedad. Una consejera en planificación familiar describió del siguiente modo el tipo de consejería que típicamente se ofrecía en su clínica antes de comenzar el proyecto:

Nuestro servicio típico era comunicar las ventajas y desventajas de varios métodos de planificación familiar, darle el mejor método al cliente, $y$, bueno, no nos metíamos mucho en lo de prevención, aunque sí mencionábamos que deberían cuidarse. A veces mencionába- 
mos lo de protegerse no sólo contra el embarazo sino también contra las enfermedades, pero no lo hacíamos con amor, no lo hacíamos para ayudar a que la gente cambiara de opinión, no era más que información. Era. nada más que un consejo: le conviene no hacer esto o lo otro. En realidad no lo discutiamos, a menos que el cliente lo pidiera. No era una consejería efectiva.

\section{- Thesla Bustillo ASHONPLAFAVHonduras}

En esa época este tipo de consejería limitado parecía ser suficiente para los servicios de planificación familiar. Pero con la aparición del VIH y el SIDA quedó claro que dichos servicios no podrían atender al tema sin adoptar una perspectiva más amplia en cuanto a la salud sexual. Una consejería eficaz sobre el SIDA requiere discusiones francas sobre sexualidad y comportamientos sexuales y un estilo mucho más personal de comunicación con el cliente. Muchos trabajadores en las APF llegaron a la conclusión de que no podían motivar a sus clientes a que tuvieran relaciones sexuales menos riesgosas sin antes atender a los factores subyacentes que influyen en la capacidad de decisión del individuo en cuanto al control de su vida sexual. Este nuevo enfoque en la sexualidad requería una serie de cambios en los modos de entrega de servicios de planificación familiar.

La meta del programa no fue simplemente añadir la prevención del VIH y las ETS a los servicios de planificación familiar, como si fuera simplemente un elemento más. Tampoco se buscaba combinar dos tipos de servicio (planificación familiar y prevención del VIH y las ETS) o "ponerlos bajo la misma carpa". El objetivo era más bien mejorar la calidad general de los servicios a través de cambios en el modo de entrega de los mismos. El proyecto buscaba alterar de una manera fundamental la naturaleza de la relación entre proveedor y cliente.

\section{Motivos por los que el personal eligió cambiar}

Para que este objetivo se concretara, fue indispensable que cada una de las APF, al nivel institucional, decidiera emprender un proyecto de integración del VIH, y que el personal recibiera cursos de capacitación para iniciar el proceso. Pero el motivo que más animó la realización del proyecto y la modificación de actitudes y prácticas fue el sen- tido de urgencia sobre la epidemia del SIDA. Como lo expresó una consejera de planificación familiar:

Uno de los factores [que motivó este cambio] más que cualquier otro fue la realidad que estamos viviendo. No podemos negar el hecho que en mi ciudad, San Pedro Sula, tenemos la más alta tasa de casos de SIDA. Acá, todos los días me encuentro con alguien que tiene SIDA, o que su esposo tiene SIDA, o que alguin tío, primo o hermano tiene SIDA O el VIH. He tenido que ver tantos casos que ya no le encuentro nada raro. Tenemos que ir más allá [de lo que estamos haciendo] si vamos a proteger a nuestra gente, a nuestro país, y al mismo ASHONPLAFA.

\section{-Yolanda Ruiz ASHONPLAFA/Honduras}

Para 1993 en América Latina y el Caribe el SIDA había dejado de ser un rumor y se había convertido en una ineludible realidad. Además de motivar al personal de las clínicas a que tomaran acción, la epidemia generó una nueva demanda entre los clientes de las APF, quienes empezaron a pedir información, consejería y servicios relacionados al VIH/SIDA. Una promotora de FAMPLAN/ Jamaica describió así las inquietudes y el temor que motivaban los pedidos de ayuda de los clientes:

Antes que esta chica muriera de SIDA, si uno trataba de hablar con aquellos muchachos, ellos realmente no tenían interés en lo que uno les decía. Pero vea que una vez que se enteraron de la muerte de esta chica, y que supieron que ella solía hablar sobre la cantidad de novios que tenía, entonces todos quedaron muy asustados.

\section{DESARROLLO DEL PROYECTO AL NIVEL INSTITUCIONAL}

Cada una de estas tres APF es muy distinta en términos de tamaño y estructura. Por lo dicho cada una elaboró un diseño más o menos singular para sus proyectos de integración del VIH y las ETS con la planificación familiar, aunque las tres incoiporaron algunos elementos comunes. BEMFAM/Brasil tiene centenares de empleados que trabajan en ocho clínicas y más de 100 puestos de salud; ASHONPLAFA/Honduras tiene cinco clínicas y un programa de ventas comunitarias; $y$ FAMPLAN/Jamaica (con aproximadamente 20 empleados incluyendo la administración) tiene 


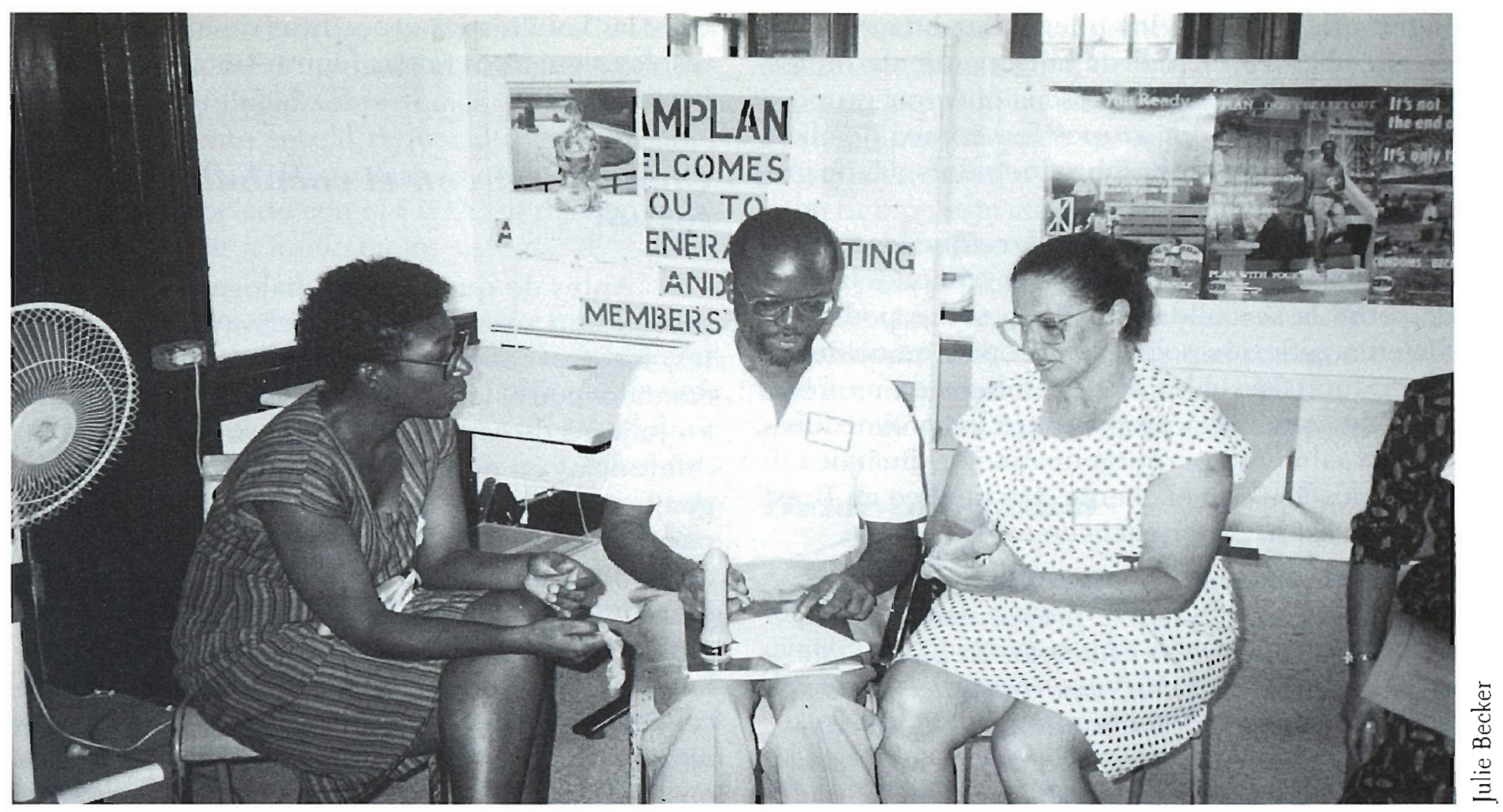

sólo dos pequeñas clínicas y un programa de extensión rural. No obstante estas diferencias, cada una de las tres APF logra servir poblaciones urbanas, rurales, de clase media y de bajos recursos económicos. Desde el comienzo del proyecto las tres APF tuvieron oportunidades para intercambiar experiencias, en base a las cuales cada una hizo modificaciones a sus propios programas y adoptó elementos de los otros.

El desarrollo de cada proyecto de integración respondió, en parte, a los resultados de evaluaciones de las necesidades locales realizadas por personal de la IPPF/WHR y los gerentes de las APF. Estas evaluaciones incluyeron entrevistas formales e informales con el personal de las APF y con clientes, además de observaciones de sesiones de consejería. La IPPF/WHR y los gerentes de las APF utilizaron esta información para determinar juntos las prioridades de cada asociación, tomando en cuenta la estructura de programas, los recursos, la organización del personal y las necesidades percibidas por cada APF.

\section{Primer paso-capacitación del personal}

En cada una de las APF, el primer paso una vez iniciado el proyecto fue la capacitación del personal conducida por consultores nacionales, profesionales propios de las APF, o representantes de la IPPF/WHR, según las necesidades y recursos de cada APF. (Desde entonces cada una de las APF ha logrado alcanzar un nivel de capacidad interna suficiente como para entrenar a sus propios trabajadores).

En cada caso los talleres de capacitación no estuvieron limitados a consejeros y educadores, sino que incluyeron médicos, enfermeras, administradores y personal de apoyo, como ser choferes y trabajadores de limpieza. La capacitación inicial, que típicamente consistía en dos o tres talleres de un día cada uno, trataba información básica sobre el VIH y las ETS, sexualidad y técnicas de consejería y educación pertinentes. Los talleres posteriores ayudaban a que los participantes entendieran y ampliaran el concepto de la salud sexual y reproductiva, que exploraran a fondo los distintos aspectos de la sexualidad, y que aprendieran nuevos métodos de comunicación para entablar estos delicados temas con el cliente. Otros talleres analizaban la temática del género y el poder en las relaciones humanas, y exploraban tácticas para fortalecer la capacidad de comunicación y negociación del cliente con su pareja sexual. También se organizaban talleres de capacitación especializados para pequeños grupos del personal. Los médicos y las enfermeras, por ejemplo, asistían a talleres sobre el diagnóstico y trata- 
miento de las ETS; los que trabajaban con grupos de clientes recibieron entrenamiento en técnicas de facilitación de discusiones en grupo; y los responsables por grupos femeninos de clientes asistieron a talleres sobre metodologías de grupo más especializadas.

Con el propósito de ayudar a que los trabajadores de las APF se sintieran más cómodos hablando sobre la sexualidad, también se les pedía que hicieran reflexión sobre sus propias emociones y experiencias sexuales. Esto resultaba en un mejor nivel de conciencia propia entre los proveedores, y eventualmente permitía una mejor dinámica de comunicación con el cliente. Un médico en Brasil resumió así su experiencia en estos talleres:

Uno puede tener los conocimientos, uno puede tomar mil cursos y prepararse a fondo, pero hay que querer hacerlo. Yo pienso que eso es el aspecto más importante del curso... tomar conciencia y sensibilizarse. Los conocimientos previamente adquiridos no sirven de nada si una no se sensibiliza.

- Dr. Vania Bastos Petti BEMFAM/Brasil

\section{TEMAS DE LA CAPACITACION}

Aunque los talleres de capacitación en cada APF respondían a las necesidades, los conocimien- tos y las habilidades específicas de los participantes, los siguientes temas fueron tratados en todos los programas.

\section{Comodidad con el vocabulario sexual}

Antes de que puedan dialogar eficazmente sobre salud sexual y reproductiva con sus clientes, los proveedores de servicios deben sentirse cómodos con el lenguaje de la sexualidad. Durante los talleres de capacitación salieron a luz grandes diferencias en el nivel de comodidad con el lenguaje sexual entre los participantes en distintos países o incluso dentro de una sola APF. Por lo dicho los talleres típicamente comenzaban con ejercicios que obligaban a los participantes a verbalizar una variedad de términos que describen actos sexuales y anatomía sexual, usando vocabularios formales y populares. Durante estos ejercicios también se discutían las diferencias entre el vocabulario usado por profesionales y el de los clientes, cuáles palabras se consideran aceptables y cuáles no, y cuáles vocablos responden mejor a las necesidades del cliente en una situación particular.

\section{Clarificación de valores}

Muchos de los miembros del personal de las

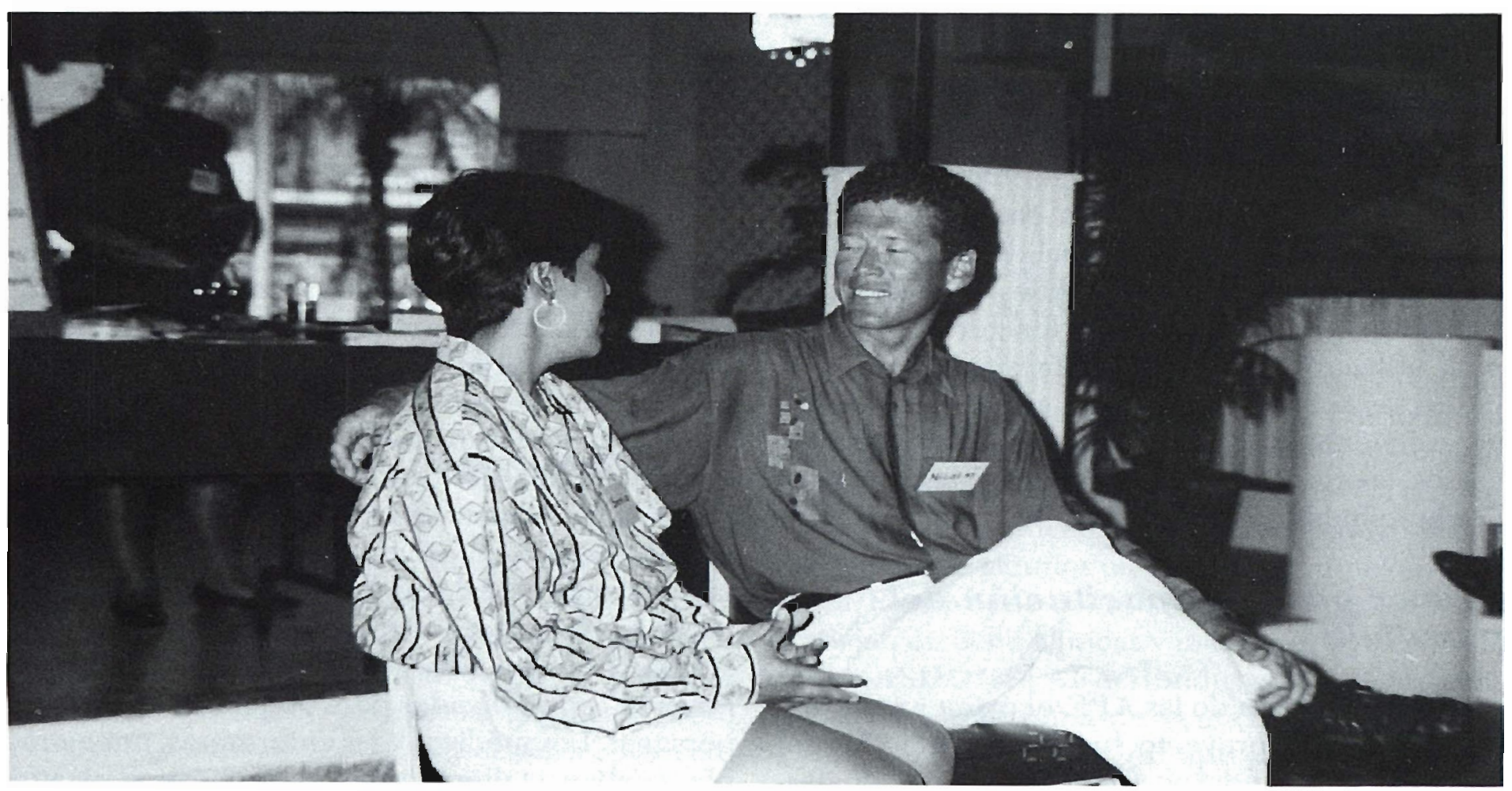


APF ya había recibido entrenamiento en la clarificación de valores. Pero dado el nivel de experiencia y la sensibilidad sobre temas de sexualidad y comportamiento sexual requeridos para atender debidamente al VIH, y tomando en cuenta el fuerte estigma asociado con el SIDA, se decidió indagar mucho más a fondo en los sistemas de valores del personal.

Uno de los ejercicios en esta etapa de la capacitación requería que los participantes consideraran una lista de comportamientos sexuales que incluía sexo oral recibido por la mujer, sexo oral recibido por el hombre, sexo en grupos, sexo anal, relaciones extramatrimoniales y prostitución. Cada participante tuvo que indicar si cada uno de esos comportamientos era aceptable para él, aceptable para otros, o simplemente inaceptable. Luego los participantes discutieron qué les parecería si otra persona decidiera que una actividad que ellos acostumbran practicar es inaceptable. En otro ejercicio, los participantes escucharon declaraciones como: "Las personas que tienen relaciones sexuales con personas del mismo sexo son anormales"; "Una mujer que no tiene educación es incapaz de tomar decisiones independientes sobre su vida sexual y reproductiva"; o "Tener más de una pareja sexual a la misma vez es aceptable". Los participantes tenían que decidir si estaban de acuerdo o no con cada declaración, y luego se les pedía que trataran de convencer a los que tenían un punto de vista diferente.

Estos ejercicios sacaron a la luz los sesgos de los miembros del personal y desafiaron las convicciones de sus colegas. Como miembros de las comunidades y las culturas en las que trabajan, los empleados de las APF suelen ser un espejo de los valores de la sociedad en general. Por ejemplo, durante los ejercicios varios participantes dijeron que ellos interpretaban ciertos actos sexuales como equivalentes a la prostitución o la homosexualidad y expresaron oprobio hacia dichas actividades y los individuos que las practican. Para el personal de FAMPLAN en Jamaica resultó difícil discutir, y mucho más aceptar, ciertos comportamientos que consideraban perversos, como ser el sexo anal. Sin embargo, una vez que comprendieron el hecho de que tanto hombres como mujeres en Jamaica practican este tipo de sexo, los participantes del taller vieron la importancia de reconocer esta práctica en sus actividades de consejería, a pesar de sus opiniones personales.

Una consejera indicó que consideraba que el sexo oral no era un comportamiento normal e inicialmente no pudo separar esta convicción de la discusión de comportamientos sanos o riesgosos en cuanto a la transmisión del VIH y las ETS. Sus colegas no lograron hacer que cambiara de opinión. Pero aunque no pudo ver más allá de sus valores personales durante los talleres de capacitación, al poco tiempo esta consejera le empezó a enseñar a sus clientes cómo cortar un condón por la mitad y usarlo para proteger a una mujer que recibe sexo oral. Obviamente, esta consejera entendió y posteriormente aceptó la idea de que su responsabilidad como profesional de salud la obliga a encarar estas realidades a pesar de sus valores personales.

\section{Desarrollo sexual}

Además de proveer información objetiva sobre sexualidad, muchos de los ejercicios de capacitación sirvieron para que los participantes recordaran sus propias experiencias de aprendizaje sexual y para que examinaran cómo esas experiencias afectaron su desarrollo emocional y físico. Durante un ejercicio se le pedía a los participantes que cerraran los ojos y recordaran el momento en la niñez cuando primero aprendieron algo sobre el sexo y las circunstancias que rodearon sus primeras emociones sexuales. Se les pidió que recordaran las cosas que sintieron a medida que fueron creciendo y aprendiendo. En Honduras, los participantes compartieron una gran variedad de memorias, tanto positivas (felicidad, curiosidad, nuevas sensaciones, deseo y amor) como negativas (ansiedad, temor, vergüenza, asco y tristeza). Todo esto ayudó a que los proveedores de servicios aprendieran de sus propias experiencias para entender mejor las inquietudes y emociones sexuales de sus clientes.

La sexualidad fue uno de los temas sobre el cual el personal de todas las APF repetidamente pidió capacitación adicional, para obtener tanto información técnica como métodos de comunicación útiles en el manejo de temas delicados. En un ejercicio se le pidió a los participantes que escribieran preguntas anónimas sobre la sexualidad, las cuales posteriormente revelaron inquietudes fundamentales que los participantes probablemente no hubieran estado dispuestos a expresar en voz alta. En una sesión se recibieron las siguientes preguntas:

- ¿Es posible tener sexo anal con una mujer?

- ¿Porqué perdí tanta sangre durante mi primer encuentro sexual?

- Ess malo masturbarse? 
- ¿Da satisfacción el sexo oral?

- Existen personas que disfrutan del estimulo sexual de su pareja pero no logran obtener orgasmos? ¿A qué se debe esto?

- ¿Porqué sienten miedo algunas mujeres en el momento de penetración?

\section{Definiendo la salud sexual y reproductiva}

Algunos talleres de capacitación fueron dedicados a explorar la variedad de significados que suelen agruparse detrás de têrminos como "salud sexual" y "salud reproductiva", con el fin de llegar a un acuerdo sobre estos conceptos en el contexto local. Durante un taller en Honduras, los participantes definieron la salud sexual así: “El aceptar nuestro propio sexo y nuestra salud general... Con una actitud positiva, tendremos salud sexual sin contagiarnos con el VIH o las ETS... Para obtener salud sexual, debemos estar sanos física, psicológica y emocionalmente". Bajo la categoría de salud reproductiva, los participantes añadieron: "El bienestar mental, social, emocional y económico de la pareja y el individuo... éstas son las condiciones óptimas para la reproducción de todos los seres humanos".

Un médico de BEMFAM/Brasil reflexionó sobre lo que significa ofrecer servicios de salud

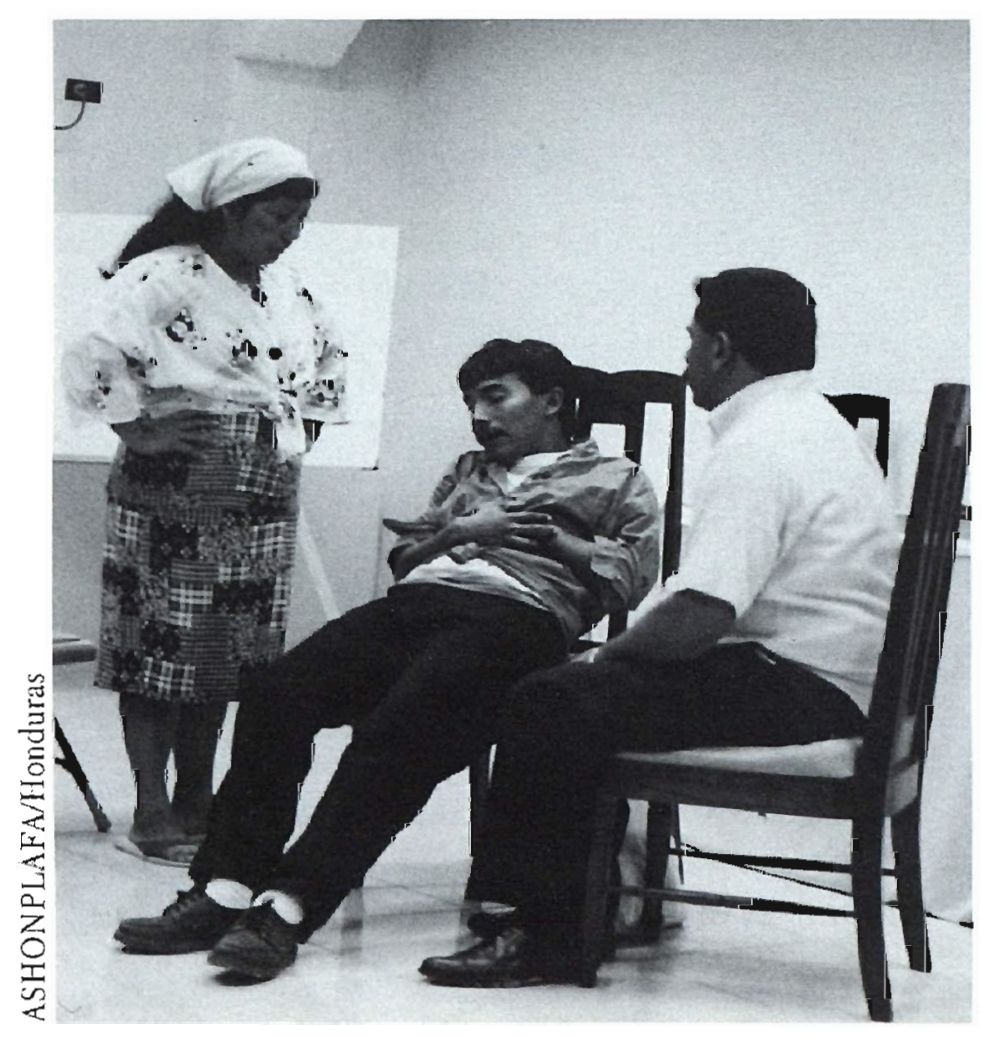

sexual y reproductiva más completos, señalando lo siguiente:

Uno puede ser un buen profesional, puede saber cómo insertar correctamente un dispositivo intrauterino, cuál remedio se debe recetar para la gonorrea, pero este [enfoque más amplio] trata de ver a la totalidad de la persona, ayudando al cliente desde una perspectiva holistica de salud y bienestar general. Yo creo que la capacitación en BEMFAM sirvió para darle esa visión a la gente.

\section{- Dr. Roberto Días Fountes}

\section{La vida sexual y percepción de riesgo del cliente}

Uno de los principales objetivos de los talleres de capacitación fue fortalecer la aptitud del personal para explorar las circunstancias individuales de los clientes, incluyendo la vida sexual de los mismos. Mediante juegos de roles, los participantes actuaron situaciones en las que le ayudaban al cliente a verbalizar sus verdaderas inquietudes sobre su vida reproductiva y sexual, y determinar por sí mismo su nivel de riesgo de infección con el VIH. Uno de los ejercicios requería que un participante jugara el papel de un asesor que no sabe nada sobre la situación del cliente. Otro participante, jugando el papel del cliente, adoptaba una serie de circunstancias personales ficticias y sólo las revelaba si la consejera indagaba a fondo. En uno de estos talleres en Honduras, los participantes exploraron las siguientes situaciones de clientes:

- Una mujer profundamente religiosa que siente mucha vergïenza. Le preocupan las ETS y el VIH porque sospecha que su esposo la engaña. Sólo está dispuesta a discutir la situación con una consejera que la hace sentir suficientemente cómoda como para inspirar confianza.

- Una adolescente visita la clínica para pedir métodos anticonceptivos. Ha sido abusada sexualmente por su tio y tiene mucho temor de hablar sobre el tema.

- Una mujer cuyo esposo la obliga a tener sexo anal cree que su esposo pueda ser homosexual.

En algunos casos la "consejera” lograba ganar la confianza del "cliente" y permitir que éste expresara sus verdaderos sentimientos. Pero cuando la "consejera" tenía menos éxito en descubrir la verdadera situación del cliente, todos los participantes del taller analizaban el caso, identificando 




tácticas que podrían haber facilitado una mejor verbalización de las vordaderas preocupaciones del cliente. Finalmente los participantes en el ejercicio definían los tipos de preguntas que más ayudan en estos procesos de exploración.

Durante otros ejercicios los participantes aprendían cómo los clientes perciben su propio nivel de riesgo y los factores que influyen en esta percepción. Mediante juegos de roles, los participantes recreaban situaciones típicas, como la de una mujer que viene a la clínica buscando un método de planificación familiar pero que nunca ha pensado sobre su propio riesgo de contraer el VIH. En este caso se le pedía a la "consejera" que tratara de comprender el nivel de percepción de riesgo de una mujer y los factores que influyen en esa percepción. Luego la "consejera" tenía que explicarle a la mujer porqué estos factores la podrían poner en una situación cle riesgo. Al analizar estos juegos de roles los participantes podían desarrollar estrategias para ayudar al cliente a comprender y evaluar su propio nivel de riesgo.

\section{Género, poder y relaciones sexuales}

Los talleres de capacitación también examinaron la manera en que la dependencia económica y las relaciones de género pueden afectar las decisiones de clientes respecto a su salud reproductiva. El propósito era encontrar y practicar maneras de ayudarle al cliente a considerar las posibles ramificaciones de sus decisiones. Durante una reciente scsión en Honduras, los participantes reunieron una lista de factores que afectan las decisiones de los clientes que incluía: temor de quedar embarazada, temor de quedar sola (abandonada por su pareja), temor a la violencia doméstica, convicciones religiosas, y la influencia o coerción directa del esposo/a o pareja.

En otros talleres los participantes analizaron las maneras en que las construcciones sociales y personales del género afectan la dinámica de las relaciones sexuales. En esta instancia los ejercicios examinaban los factores que pueden causar un desequilibrio en la dimensión del poder en una relación. Durante los juegos de roles se trataba de crear situaciones de comunicación y negociación sexual en relaciones desequilibradas. Otros ejercicios permitían que el personal reflexionara sobre las ventajas y desventajas de ser hombre o nujer en el contexto cultural local, y sobre cómo estos factores sociales influyen en las relaciones sexuales.

\section{Sexo sin riesgos}

Los talleres de capacitación también generaron estrategias para ayudarle a los clientes a entablar el tema de las relaciones sexuales o el uso cle condones con sus parejas. Se habló de cómo el momento y las circunstancias en las que se introducen estos temas pueden determinar en gran 
medida el éxito de la conversación posterior. En Jamaica, los participantes en el taller reunieron una lista de excusas que la gente típicamente ofrece para evitar el uso del condón; luego elaboraron una lista de "argumentos a favor" que se podrían usar en el proceso de negociación. Con el propósito de entender mejor las dificultades que este proceso puede generar para el cliente, los participantes también actuaron en juegos de roles en los que distintas parejas negociaban las pautas de sus relaciones sexuales.

Los talleres exploraron el sexo sin riesgos en el sentido más amplio; es decir, no sólo en términos de protección contra el VIH y las ETS, sino también en contra de embarazos no deseados y abusos del poder. Los participantes discutieron opciones de expresión sexual sin riesgos y participaron en ejercicios que promovían creatividad en la definición de nuevas categorías de expresión sexual que no incluyen penetración y coito. En Jamaica, por ejemplo, los participantes elaboraron una lista de "expresiones sexuales" que incluía actividades como masajes, leer poesía, y tomar baños en pareja.

\section{La planificación familiar desde una perspectiva de salud sexual y reproductiva}

En estos ejercicios el personal analizó todos los métodos de planificación familiar no sólo en base a su eficacia en la prevención de embarazos o las ETS, sino también según su efecto en las relaciones sexuales y el placer sexual. También se discutieron las ventajas y desventajas de usar condones exclusivamente como método de planificación familiar y la posibilidad de usar condones con otros métodos anticonceptivos.

Una serie de ejercicios más específicos tuvo como propósito examinar los sesgos personales y profesionales de los participantes en contra del condón como método, y de encontrar maneras de mejorar la imagen de este método entre los clientes. Antes de los talleres de capacitación, muchos participantes jamás habían demostrado el uso correcto del condón ante sus clientes. En el taller se utilizó un modelo de pene y se practicó todo, desde cómo abrir el paquete del condón hasta cómo desecharlo.

\section{Enfermedades de transmisión sexual}

Uno de los principales objetivos de la capacitación en todas las APF fue asegurar un conocimiento básico de todas las ETS que ocurren en el contexto local. Las consejeras aprendieron a ayudarle al cliente a reconocer lo que es normal o anómalo, y a indagar sobre las ETS que cada cliente ha contraído en el pasado. También aprendieron sobre el peligro de recomendar un DIU para mujeres que corren riesgo de contraer una ETS y sobre las infecciones asintomáticas-información que muchas consejeras desconocían. La capacitación sobre ETS para el personal médico y de enfermería fue más detallada, abarcando el reconocimiento clínico de las ETS, el diagnóstico y el tratamiento.

\section{EL PROCESO DE CAMBIO ENTRE LOS PROVEEDORES}

Estoy conciente de que estoy sirviendo con más interés y dedicación a mis clientes porque no estoy hablando sólo acerca de un método, sino más bien sobre la prevención de una enfermedad. Esto me hace sentir bien.

\section{- Thesla Bustillo}

Es evidente en lo anterior que esta consejera siente mucho orgullo en su trabajo. Durante los tres años entre 1993 y 1996 los miembros del personal de ASHONPLAFA/Honduras, BEMFAM/ Brasil y FAMPLAN/Jamaica crecieron profesional y personalmente a medida que cambiaron su modo de trabajo. En efecto, crearon una nueva misión para sus asociaciones. Durante este período los proveedores también vieron un alarmante cambio en la naturaleza de las preguntas e inquietudes de sus clientes. Este cambio se debía en gran medida al crecimiento de la epidemia del SIDA, pero también reflejaba el nuevo enfoque en la entrega de servicios de las APF.

Por supuesto que el cambio es un proceso que no ocurre de noche a día. La historia de este proceso de evolución surgió durante entrevistas con varios miembros del personal de las APF_ _ coordinadores de programas, consejeras, trabajadores de extensión, médicos y enfermeras - quienes hablaron con entusiasmo genuino sobre cómo ayudan a los clientes a resolver problemas que van más allá de la simple selección de un método. Por ejemplo, un doctor de BEMFAM/Brasil describió cómo el nuevo programa le permite extender su papel más allá de la atención médica:

Estoy seguro que en otras clínicas, probablemente en la mayoría, los doctores colocan los DIU y recetan remedios para la gonorrea tan bien como lo hago yo. Al fin y al cabo no es 


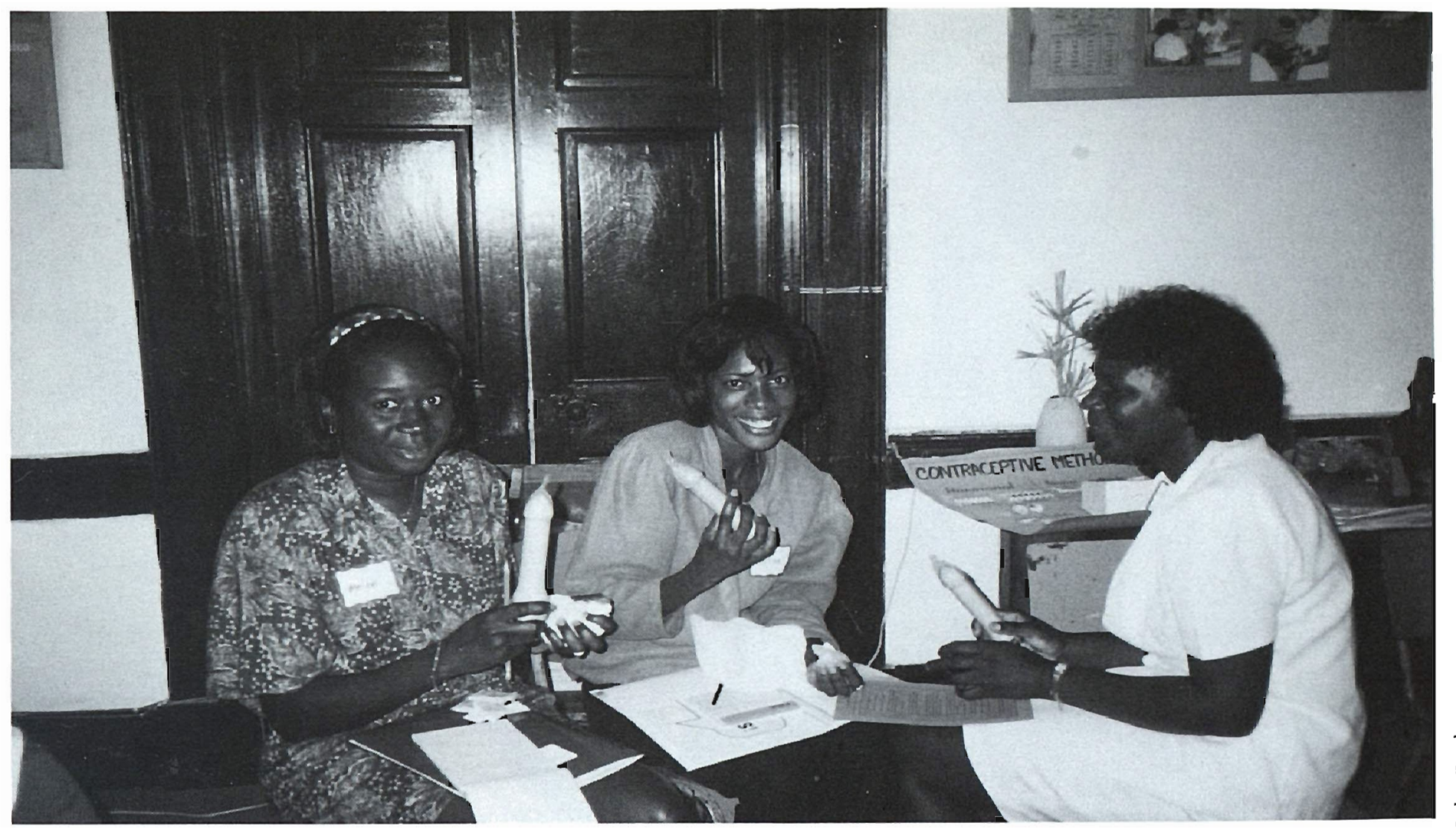

muy dificil —uno sigue procedimientos, se fija en un texto y ahi está. Pero preparar el lado emocional de la gente... esto nos obliga a pensar de un modo distinto, a enfrentar las emociones de los otros. Es decir que ahora también atendemos a las emociones de la gente. En este sentido hemos logrado vencer nuestros prejuicios y nuestras limitaciones.

\section{-Dr. Roberto Días Fountes}

Junto con esta nueva manera de dar consejería y relacionarse con el cliente, los miembros del personal hablaron cle un nuevo nivel de conciencia propia entre sí y entre sus clientes:

Antes hablábamos sobre métodos y llegábamos a un acuerdo sobre un método con el cliente. Pero ahora vamos mucho más a fondo. Le preguntamos si ticne una infección... averiguamos si tiene factores de riesgo... podemos hablar sobre otras cosas, como ser relaciones sexuales, su vida sexual en general, sobre sus parejas, ino cierto? En algunas ocasiones hasta le pregunto al cliente quién toma la iniciativa en sus relaciones sexuales, y cómo se siente al respecto... He descubierto que las mujeres quieren más... quieren saber mais sobre si mismas.

-Yolanda Ruiz

\section{Reconsiderando los métodos de planificación familiar}

Como consecuencia del nuevo enfoque los proveedores pudieron ampliar la consejería sobre métodos anticonceptivos; además de la descripción básica de cada método, las consejeras ahora ofrecen una explicación de la relación que cada método tiene con la transmisión del VIH y las ETS. Las consejeras enfatizan los beneficios dobles del condón (como anticonceptivo y protector contra el VIH y las ETS), y también proponen la opción de usar condones junto con otro método de planificación familiar. Según el director ejecutivo de FAMPLAN/Jamaica:

Los problemas de los métodos de planificación familiar y la amenaza del VIH y las ETS son cada vez más complejos. Hoy en dia nuestro personal debe discutir la relación entre los métodos de planificación familiar y la. transmisión del VIH y las ETS. Nosotros hacemos hincapié en la importancia del condón, y los clientes pueden elegir si quieren usar dos métodos o depender del condón para los clos tipos de protección.

\section{-Peggy Scott \\ FAMPLAN/Jamaica}

Antes del programa también era menos pro- 


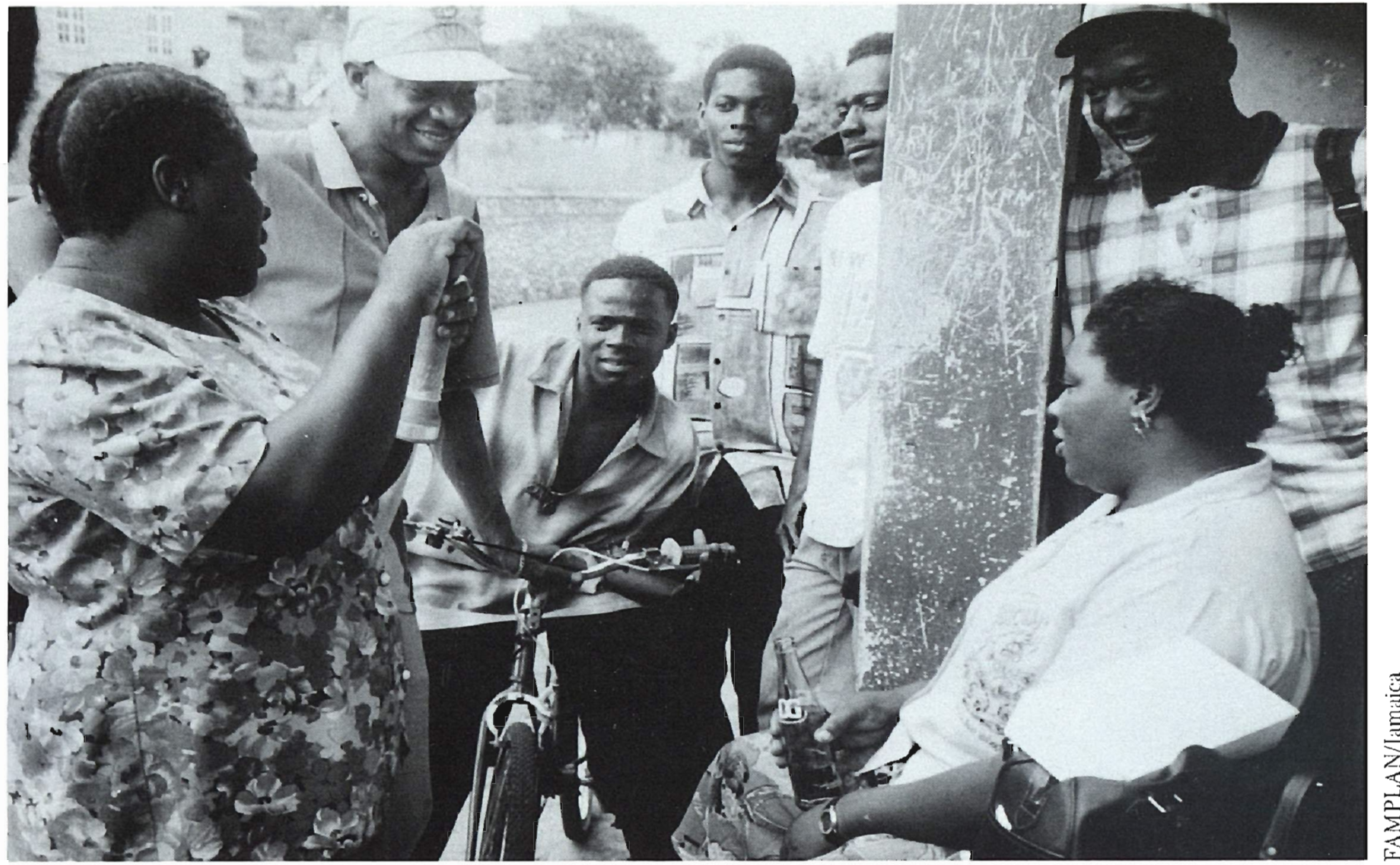

bable que las consejeras preguntaran sobre factores que podrían causar complicaciones para mujeres que usan un DIU, como ser parejas múltiples o una historia clínica de ETS. De acuerdo con Gloria Flores, una consejera en ASHONPLAFA/Honduras, en épocas anteriores es posible que algunas mujeres hayan recibido indebidamente un DIU porque no se prestó atención a su riesgo de contraer una ETS. Otra proveedora en Honduras describió el caso de una consejera que le mostró a una mujer que el condón la podría proteger mejor que un DIU

Habia una mujer de unos 33 años que habia estado usando condones como método anticonceptivo durante los uiltimos 5 años. Su esposo... habia estado en Choluteca por unosno me acuerdo lo que me dijo-8 o 9 meses, cuando ella se dio cuenta que el estaba involucrado con una mujer de ahi. Cuando ella se enteró quiso "darle una recompensa"así lo dijo-darle una sorpresa... el regalo sería colocarse un DIU para que el no tuviera que seguir usando condones. Ella quería colocarse el DIU a pesar del riesgo que corría de contraer una ETS en consecuencia de la

relación que su esposo tenía con la otra mujer. jY esta era una mujer con un alto nivel de educación! Pero al final lo discutimos un buen rato y ella llegó a la conclusión de que su esposo tendría que seguir usando condones.

\section{-Yolanda Rui}

Además de discutir la relación entre métodos de planificación familiar y la transmisión de enfermedades, las consejeras ahora hablan de cómo algunos métodos, según las preferencias del individuo, pueden aumentar el placer sexual y mejorar una relación. Las consejeras enfatizan que el anticonceptivo provee un sentido de seguridad al proteger tanto contra el embarazo como la enfermedad, ya que elimina la ansiedad sobre consecuencias desagradables y permite que la pareja disfrute más de su relación sexual.

\section{El redescubrimiento del condón}

Una de las consecuencias más notables del programa fue la manera en que los proveedores mismos llegaron a ver el condón, tanto en sus vidas personales como en lo profesional. Tradicionalmente, el ámbito profesional de la planificación 
familiar ha tenido un sesgo en contra de los condones. Esto surgió de la percepción histórica de que los condones eran menos eficaces que otros métodos de planificación familiar, aunque en realidad resulta que pueden ser sumamente eficaces en la prevención del embarazo cuanclo se los utiliza correcta y consistentemente. Sin embargo, las dudas sobre la eficacia de los condones en "uso típico" (reconociendo que el condón siempre depende del la acción del usuario), junto con el mayor valor que se le claba a los métodos de larga duración en cuanto a las metas de reducción de fertilidad, hicieron que algunos proveedores no promovieran activamente el condón.

Al comenzar el proyecto, los directores de programas en cada una de las tres APF encontraron que el personal se resistía a promover condones. Aunque esta reacción se puede haber debido a las dudas sobre la eficacia del condón, los directores reconocieron que también operaba una tendencia de los profesionales de planificación familiar de juzgar al condón de un modo distinto, más allá de la capacidad del método de prevenir el embarazo o el VIH y las ETS.

Nosotros le damos distintos valores a cada uso del condón [prevención del embarazo versus. protección contra el VIH y las ETS] porque venimos de una perspectiva de planificación. familiar. Todavia vemos las cosas desde el punto de vista de los embarazos no deseados. Queda claro que estamos pasando juicio y que nos resistimos a cambiar nuestros puntos de vista a razón de nuestra historia como proveedores de planificación familiar.

\section{-Rita Badiani BEMFAM/Brasil}

El sesgo en contra del condón era tal que muchos proveedores creían que este método era menos eficaz de lo que es en realidad. Cuanclo los capacitadores en Jamaica y Honduras le preguntaron al personal cuál pensaban que era el nivel porcentual de eficacia del condón, las respuestas generalmente fueron comparables o inferiores al verdadero nivel registrado con "uso típico" de condones.

Antes de que comenzara el nuevo programa, los proveedores promovían el condón principalmente como un método "de respaldo" o como el método de última instancia cuando no se pudiera optar por otros. Algunas consejeras llegaban a mencionar el papel de los condones en la prevención de las ETS, pero la mayoría nunca había abierto el paquete de un condón para que el cliente lo tocara; me- nos todavía habían tratado de mostrar cómo colocarlo correctamente. Una consejera en ASHONPLAFA/Honduras dijo que "Antes hablábamos sobre el condón muy superficialmente, sin hacer ninguna demostración... Antes, la verdad es que lo veíamos sólo como un modo de evitar el embarazo... y pensábamos que era menos eficaz que otros métodos".

Tomando en cuenta todos estos sesgos, ¿cómo fue que las actitudes de los proveedores llegaron a cambiar? El Director Méclico de BEMFAM dijo que la capacitación fue lo que más le ayudó al personal a dejar atrás las percepciones negativas del condón:

Durante la capacitación se discutió todo: cómo usar y almacenar el condón, lubricantes, aspectos eróticos. ¡El capacitador hasta nos contó sobre ciertas prostitutas que saben colocar un condón con la boca! Todo esto hiæo que cambiara la manera en que el personal hablaba sobre los condones. Antes decian "aqui tiene un condón". Ahora le piden al cliente que coloque un condón en un modelo de pene y le explican cómo deben almacenarlos. Le explican que los condones pueden realiar una relación sexual porque le dan una oportunidad a la mujer para conocer mejor el cuerpo del hombre, y porque a veces hasta intensifican la experiencia sexual. Ahora vemos un aumento en el nivel de uso del condón. Después de la capacitación, jlos miembros del personal empezaron a pedirlos para uso propio!

$$
\begin{aligned}
& \text {-Dr. Ney Costa } \\
& \text { BEMFAM/Brasil. }
\end{aligned}
$$

Es más, algunos de los proveedores que usan el condón dijeron que la experiencia personal les ayudó mucho en el momento de cxplicarle el uso correcto a un cliente. Por ejemplo, un trabajador de extensión de FAMPLAN explicó que "cuando uno sale a hablarle a la gente, casi siempre alguien pregunta 'Y Ud., ¿usa el condón?'. Es decir que antes de salir a hablar uno tiene que empezar a practicar: No se le puede mentir a la gente; uno tiene que ser honesto con sí mismo". Otra trabajadora de extensión recordó con orgullo el día en que su hijo le piclió un condón y un folleto informativo para que pudiera llevarlos a la escuela y compartirlos con sus amigos durante el recreo.

A medida que cambiaron las actitudes hacia el condón, los proveedores encontraron nuevas e innovadoras maneras de promoverlos. Las técnicas que emplean y la información que proporcionan al respecto en la actualidad son muy 
distintas de lo que anteriormente se consideraba normal.

Antes distribuiamos condones sin ninguna explicación. Ahora le pedimos al cliente que toque el condón para ver lo suave que es. A las mujeres les decimos que ellas también pueden participar, que colocarle un condón a su marido puede ser una parte agradable del acto sexual. Antes habia resistencia. Las mujeres solian pasar los condones de una a otra como carbón ardiente. Ahora los llevan en la cartera. Hoy el personal realmente cree en el condón.

\section{- María Elena de Pérez ASHONPLAFA/Honduras}

Una consejera de BEMFAM/Brasil juntaba condones que habían sido usados en demostraciones anteriores y los ponía en una caja. Durante las sesiones de asesoramiento en grupo, la consejera le pedía a las participantes que cerraran los ojos y les hacía pasar la caja de una a otra. Cada mujer debía comentar sobre lo que sentía en la caja. Muchas usaban palabras como "húmedos", "suaves", "olor agradable", y "fuertes", todas palabras que demostraban connotaciones positivas y ayudaban a que las participantes volvieran a considerar sus opiniones sobre el condón.

Según un miembro del personal de BEMFAM/Brasil, "En la actualidad nosotros a menudo compartimos anécdotas e ideas sobre el condón. Tratamos de destruir los prejuicios que existen en contra del condón, les damos un matiz erótico y promovemos la participación de la mujer en el uso del condón". Otro trabajador en BEMFAM dijo que "Nosotros ahora tratamos de corregir el mito de que los condones limitan el placer sexual y promovemos nuevas técnicas para el uso sensual del condón como parte del acto sexual".

La simple introducción de demostraciones sobre el condón utilizando un modelo de pene hecho de madera influyó profundamente en la calidad de la comunicación sobre el condón entre las consejeras y los clientes. El modelo invariablemente capturaba la atención de los participantes y además ayudaba a disipar la tensión. Según un trabajador de extensión en FAMPLAN/Jamaica, "Ni bien uno sale y saca el modelo de pene, todo el mundo presta atención... incluso si la gente está pasando y lo ven de lejos, siempre se acercan para ver de qué se trata".

Los trabajadores de extensión en Jamaica también elaboraron estrategias para comprobar la confiabilidad del condón. Unos inflaban condones como globos o los colocaban sobre la boca de una canilla de agua para demostrar que se los puede llenar completamente de agua sin que se rompan; otros le pedían a un voluntario que se pusiera un condón sobre el pie como una media-una inolvidable manera de mostrar la fuerza y elasticidad del preservativo. Este tipo de demostraciones logra entretener y divertir a la vez que informa sobre un tema serio. Los miembros del personal siguen probando distintas estrategias de este tipo, y siempre comparten las más exitosas entre sí.

En años recientes los clientes tradicionales de las APF también han empezado a mostrar más interés en los condones. Casi todos los clientes se llevan condones cuando se los ofrece como muestras gratuitas, y algunos vuelven para pedir más. Los trabajadores de extensión rural en Jamaica han quedado asombrados por el afán con que algunos hombres solicitan condones. Como miembros de las comunidades que sirven, los trabajadores de extensión han ganado la confianza de sus vecinos al estar disponibles para contestar preguntas o proveer condones después del horario oficial de atención. Varios de estos trabajadores cuentan cómo algunos de estos clientes desesperados los despiertan en el medio de la noche. Según un trabajador, "A las 3 de la mañana uno les oye llamar, ¡Enfermera!' Los escucho golpear la puerta a cualquier hora de la noche... Vienen y piden que una se levante, dicen 'disculpe que la despierte pero no tengo nada y necesito algo para protegerme"”. Una trabajadora dijo que la demanda para sus productos aumenta durante los días feriados: "El lunes después de Pascuas, ¡casi no me dejan dormir!”

\section{¿Qué tiene que ver el sexo? ¡Mucho!}

Con el fin de comprender mejor la situación particular de un cliente o para proveer información específica sobre la utilización del condón, los proveedores tuvieron que atender más minuciosamente a los temas de sexualidad. Antes de empezar el programa, cuando la mayoría de los trabajadores en planificación familiar se enfocaban exclusivamente en el riesgo de embarazo no deseado, la consejería solía resaltar los aspectos biológicos del coito en vez de los aspectos emocionales de la sexualidad. Pero la epidemia del SIDA ha forzado un cambio en esa perspectiva.

El problema del VIH y las ETS nos ha ayudado a enfrentar la sexualidad de una mane- 


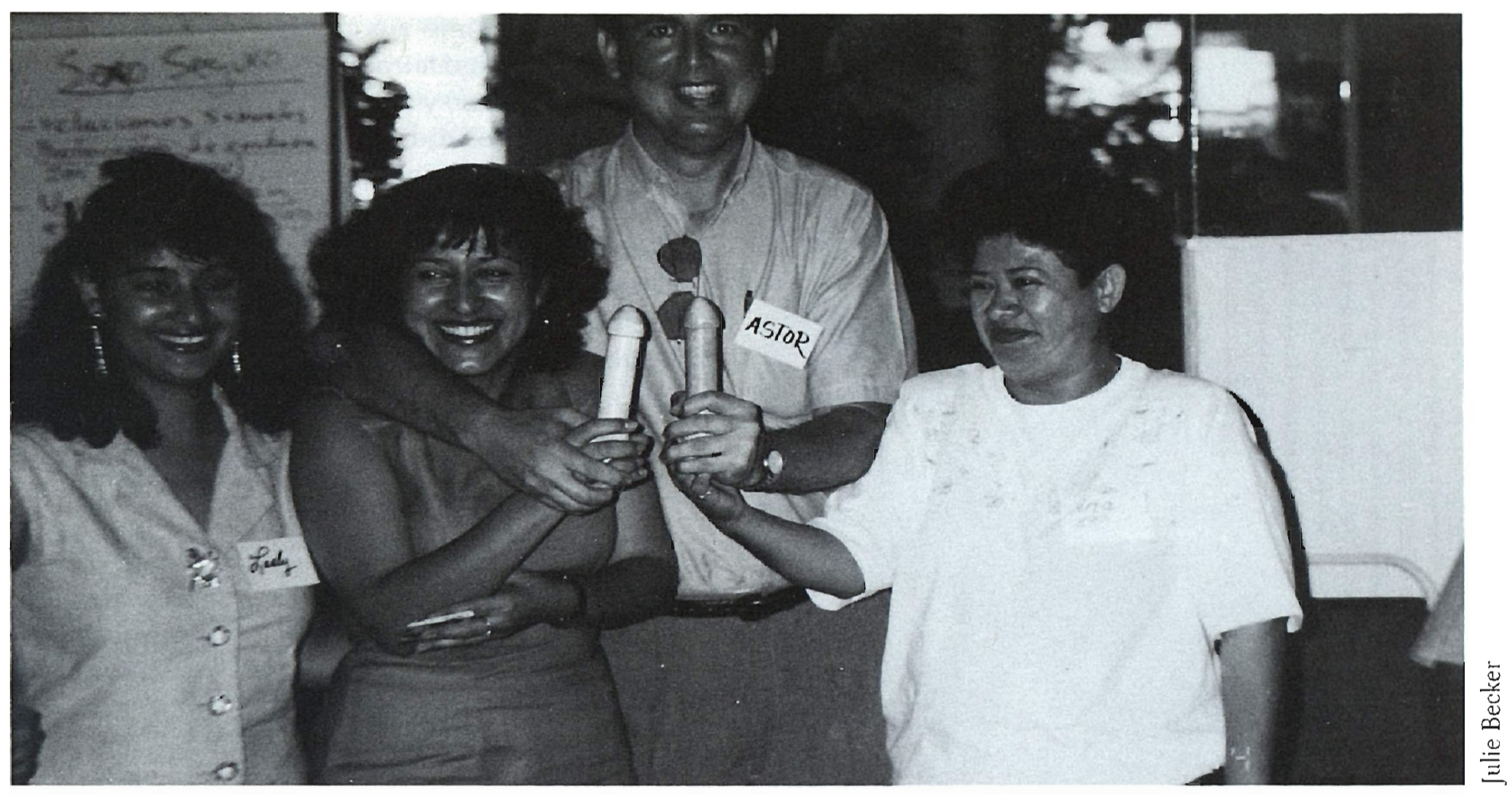

ra más activa. Cuando sólo ofreciamos consejería en planificación familiar, limitábamos lo que decíamos sobre sexualidad a ese marco de referencias. Como resultado de lla consejería integrada] hemos "sexualizado" nuestro trabajo.

\section{-Rita Badiani}

Al principio muchos proveedores dijeron sentirse incómodos al tener que hablar sobre la totalidad de las actividades sexuales en que la gente participa. Muchos no estaban dispuestos a indagar en la vida sexual de los clientes, dado que consideraban intrusas y poco apropiadas dichas preguntas. Un proveedor en Brasil recuerda la dificultad que tuvo en aceptar la homosexualidad femenina: "Yo tenía prejuicios muy fuertes sobre esta cuestión y tuve que trabajar duro para vencerlos... Pienso que aunque todavía no he logrado una victoria del $100 \%$ en este sentido, he alcanzado un $90 \%$ de mi objetivo en cuanto a mi actitud frente a la homosexualidad femenina. Esa fue mi mayor dificultad". Para otros proveedores el mayor desafío fue aceptar la sexualidad entre adolescentes. Por ejemplo, la recepcionista de FAMPLAN/Jamaica, cuando veía llegar mujeres jóvenes vestidas con uniformes escolares, las mandaba a casa para que se cambiaran, porque no le parecía bien reconocer en público que las colegialas son sexualmente activas.

Poco a poco los proveedores se mostraron más dispuestos a aceptar el abanico de la expresión sexual humana en todas sus variedades. A muchos trabajadores inicialmente les sorprendió la rapidez con que los clientes respondían a preguntas sobre sexualidad. Era evidente que muchos clientes estaban más que dispuestos a compartir sus inquietudes y exteriorizar emociones sobre temas sumamente delicados. Varios miembros del personal de FAMPLAN/Jamaica, por ejemplo, al principio no podían creer la franqueza con que los clientes abordaban temas supuestamente tabúes como la homosexualidad, el sexo anal u oral, las relaciones extramatrimoniales entre tanto hombres como mujeres, la impotencia, problemas de eyaculación prematura, el abuso sexual y la violencia doméstica:

Lo que a veces nos sorprende mucho es cuando nos cuentan lo que está pasando ahora mismo... Hubo una joven que vino y dijo que era lesbiana y que quería comprar uno de los nuevos preservativos que protegen contra la transmisión del VIH durante el sexo oral entre mujeres. No tuvo ningún problema con decirme eso, a pesar de que recién nos acabábamos de conocer.

\section{Tareas preparatorias}

No cabe duda que muchos miembros del personal de las APF, quienes fueron formados en sociedades conservadoras donde no se hablaba sobre el sexo en forma abierta, tardaron un tiempo 


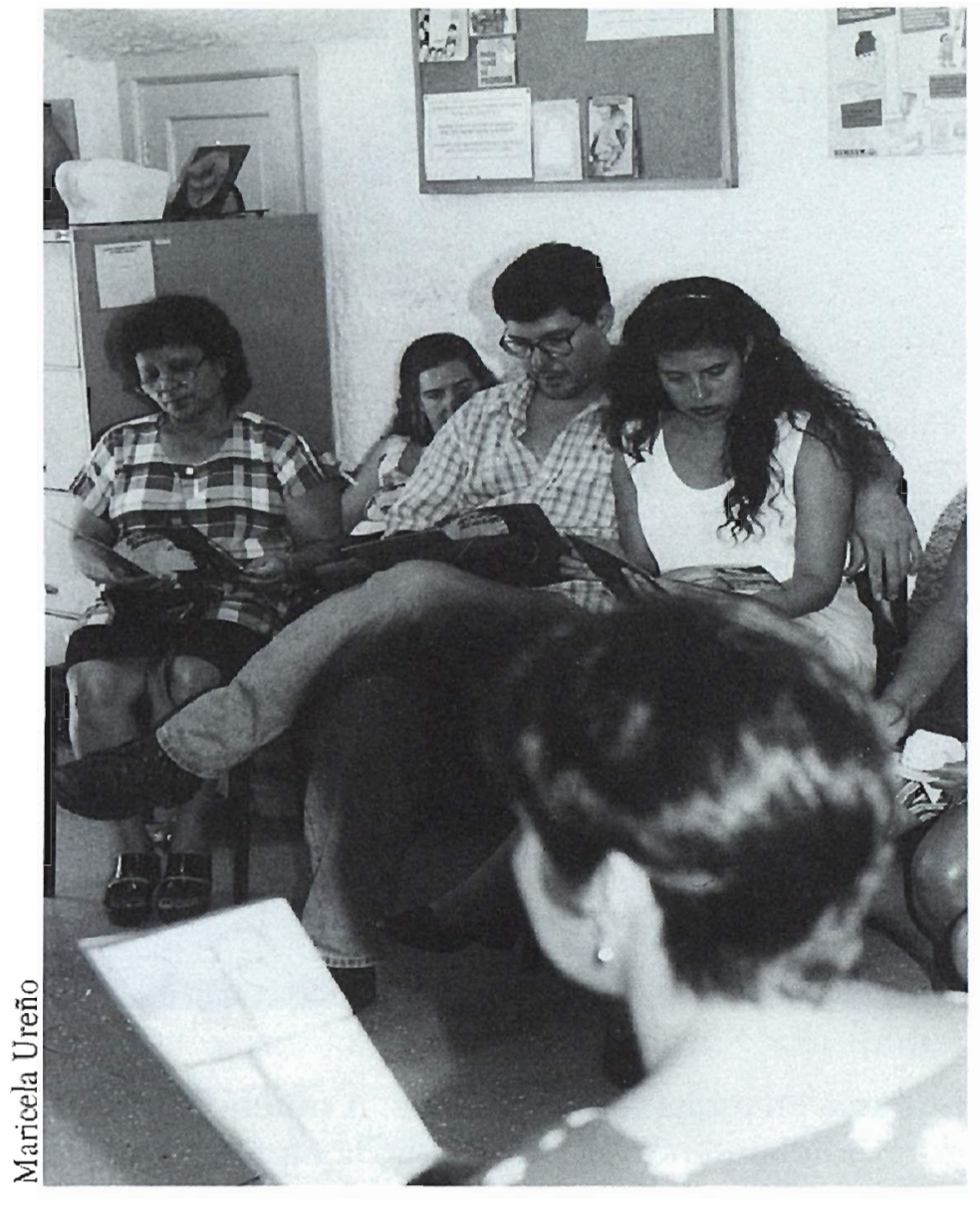

en acostumbrase a esta nueva manera de hacer las cosas. En cada uno de los tres países que participaron en el programa, los miembros del personal pidieron participar en clases adicionales de capacitación en sexualidad, dado que todavía encuentran situaciones doncle no se sienten capaces de responder adecuadamente a una inquietud del cliente. Por otro lado, algunos proveedores dijeron que la mayor comodidad con temas de sexualidad que sienten en el trabajo los ha beneficiado en su vida personal:

A mi me criaron en un ambiente donde no habia... mucha información sobre [sexualidad]. ¡My hija de 10 años me está haciendo preguntas cuyas respuestas yo no conoci hasta que vine a trabajar aqui en ASHONPLAFA! Pero ahora me puedo acercar a estos temas con tanta naturalidad que ya no siento verguienza cuando tengo que hablar al respecto... con cualquier persona, ya sean mis colegas, los clientes, my familia, mis amigos.

\section{- Gloria Flores}

ASHONPLAFA/Honduras

El resultado final de la "sexualización" de la sesión de consejería es que los clientes logran com- prender mejor cómo sus propios comportamientos sexuales pueden aumentar ambos tipos de riesgo: el del embarazo y el de infección con el VIH o las ETS. Los proveedores que emplean este tipo de consejería dicen que muchas mujeres se muestran aliviadas al encontrar una persona comprensiva en la que pueden confiar. Muchos proveedores dicen que sienten orgullo por el hecho de que pueden ayudar a que una mujer se de cuenta que sus inquietudes son "normales" y que no es la única que enfrenta problemas de índole sexual.

\section{Decisiones sobre temas sexuales}

Anteriormente, los proveedores típicamente empezaban una sesión de asesoramiento con una presentación estandarizada sobre los métodos de planificación familiar. En la actualidad casi siempre empiezan con un exploración de las circunstancias del individuo, incluso su vida sexual. A medida que el proveedor conversa con la mujer acerca de las relaciones actuales y la historia sexual de la última, los dos empiezan a evaluar el nivel de riesgo de la mujer-una transición que suele no ser fácil ni cómoda para el proveedor.

Pero no obstante las dificultades, los proveedores saben que una atención directa y honesta a los temas de la sexualidad permite, en el plazo largo, que la mujer evite tanto la enfermedad como el embarazo no deseado. La consejera recuerda una sesión que empezó de modo rutinario y probablemente hubiera permanecido en un plano puramente clínico si la consejera no le hubiera preguntado a la mujer porqué decidió hacerse una prueba de Papanicolao:

Cuando le pregunté porqué habia pedido la prueba, si era una prueba de rutina o si pensaba que tenía algún problema, una secreción vaginal... ella me dijo, "mire señorita, yo tengo un problema nuy grande que nunca se lo he contado a nadie. Pero ahora que Ud. me pregunta..." Resulta que ella no vino a hacerse la prueba para averiguar si tenía un problema médico, sino más que nada para ver si alguien la podía ayudar.. Me dijo que habia sido violada a los 15 años y que a los 18 se habia casado. En 6 años de matrimonioahora tenia 24 años de edad-jamás habia conocido lo que es un orga.smo... y nunca sentía deseos sexuales.

Al contestar mis preguntas ella sintió que habiamos creado un espacio donde podía. 
hablar de esas cosas... Pienso que si no le hubiera preguntado esas cosas, probablemente no hubiéramos tenido la oportunidad [de conversar] porque la estaban por mandar a pagar la consulta y luego a ver al doctor, y entonces todo hubiera terminado ahí. Hubiéramos discutido los resultados de su examen, en vez de hablar sobre lo que en realidad le importaba. Es decir que primero hay que explorar, ¿no? Ella no me dijo inmediatamente que la habian violado. Fue por medio de la exploración que apareció lo de la violación y todo lo demás.

\section{-Gloria Flores}

En una sesión de consejería conducida por una enfermera de FAMPLAN/Jamaica, al preguntarle a una mujer cómo se sentiría si supiera que su novio tenía otras parejas, la mujer dijo que ya sabía, iporque su novio estaba casado! La mujer en la clínica era "la otra mujer". Durante la conversación posterior quedó claro que la mujer tenía un bajo nivel de autoestima, y que en su posición de "otra mujer" se sentía incapaz de exigir que su pareja usara condones. En este caso, el proceso de exploración resultó ser la clave para comprender tanto los sentimientos como las necesidades del cliente.

Muchos clientes enfrentan serios obstáculos sociales, culturales, económicos y de género en cuanto tratan de usar condones. Muchas mujeres dependen económica y socialmente de sus maridos o novios, por lo cual no tienen el poder para insistir que ellos usen condones. Una coordinadora de programas para FAMPLAN/Jamaica lo explicó así: “Muchos de nuestros clientes son mujeres de bajos ingresos. No tienen poder. Los hombres están dispuestos a golpearlas para obtener sexo. Y también golpean a las mujeres que les piden usar el condón". La coordinadora dijo que el uso de condones es especialmente crítico en el contexto jamaicano, donde es común que tanto hombres como mujeres tengan relaciones sexuales fuera de su relación principal, y donde ambos miembros de una pareja suelen estar concientes de dichas relaciones.

Una consejera con ASHONPLAFA/Honduras recordó las dificultados que surgieron al tratar de superar las actitudes tradicionales hacia el género que limitan la capacidad de las mujeres hondureñas de negociar el uso de un método anticonceptivo con sus parejas:

Para nuestros clientes, las cuestiones de género son las que más dificultan [el uso de mé- todos]... Generalmente es el hombre el que toma las decisiones. Ellos deciden todo y es difícil porque ellos piensan, por ejemplo, que los condones sólo se usan con prostitutas o mujeres baratas... Es difícil hablar con una mujer y saber que porque está casada no va a querer siquiera llevarse un condón, porque siempre va estar pensando "¿pero qué va a pensar mi marido?"... La mujer hondureña sufre muchísima opresión, es violada a veces porque ni siquiera puede negociar las condiciones de su hogar, mucho menos de su vida sexual, del acto sexual, o de su seguridad básica... No puede negociar con el hombre porque teme que va a quedar abandonada o rechazada.

\section{-Yolanda Ruiz}

En muchos casos, una de las primeras consideraciones para la mujer durante la consejería puede ser cómo se siente sobre la posibilidad de un embarazo futuro, tomando en cuenta su riesgo percibido de contraer una enfermedad. En situaciones donde el aborto es inaceptable, inasequible o peligroso, la mujer deberá evaluar su capacidad de asegurar que su pareja usa condones correcta y consistentemente. En estos casos la consejera puede explorar la naturaleza de la relación entre la mujer y su pareja, tomando en cuenta sus niveles de dependencia económica y emocional.

Si la mujer teme que su pareja se niegue a usar condones, la consejera puede ayudarla a determinar si piensa que lo puede hacer cambiar de opinión. Pero además de la posibilidad de que el hombre se niegue, la mujer también puede temer que su pedido lo provoque a la violencia o el abuso sexual. Los proveedores deben entender que la mujer también corre el riesgo de que su pareja simplemente la abandone, lo cual podría tener consecuencias económica y emocionalmente devastadoras.

Además es posible que la mujer tenga su propio sesgo en contra del condón, basado en supuestos sobre la eficacia o aceptabilidad del método. Puede ser que la mujer piense que el condón disminuye el placer sexual, o que lo asocie con la prostitución o la inmoralidad. Y por último, es posible que la decisión de la mujer se vea afectada por consideraciones económicas y prácticas. En el momento en que tenga que decidir si va a usar dos métodos simultáneamente o sólo uno, por ejemplo, es posible que su decisión sea determinada por el costo y la inconveniencia de comprar más de un método. 


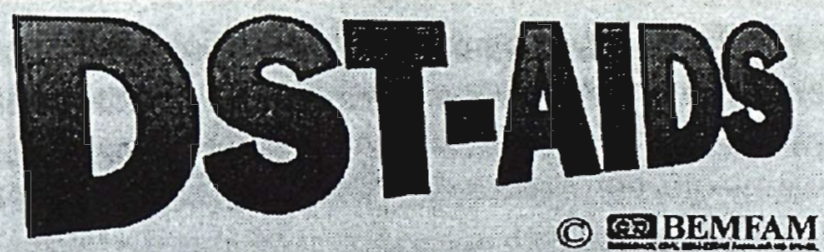

A TURMA PODE FICAR. PREVENIDA!

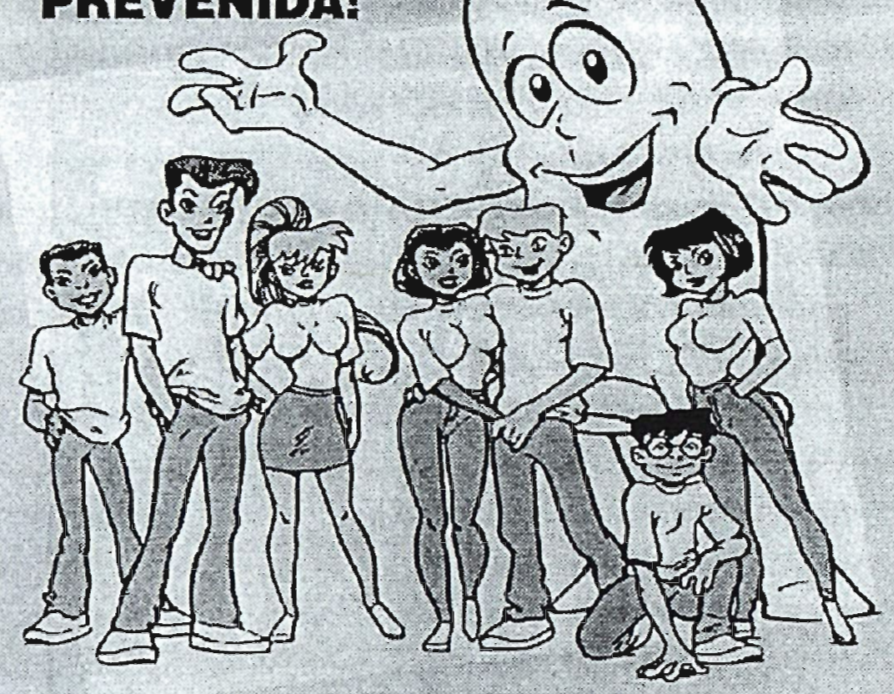

El ejemplo a continuación pone de relieve la importancia de evaluar los factores subyacentes que influyen en las decisiones anticonceptivas del cliente y en su capacidad de protegerse contra la enfermedad.

En la clínica de ASHONPLAFA/Honduras, la mujer le pidió un DIU a la consejera ni bien se habían sentado. Pero después de unos minutos y varias preguntas, la consejera descubrió que la mujer también estaba preocupada por la posibilidad de contraer una ETS por medio de su esposo, quien viajaba muy a menudo. Otras preguntas revelaron que la mujer había recibido atención médica para curar una infección varios meses atrás.

Cuando la consejera le preguntó a la mujer si alguna vez había usado condones, la mujer dijo que sentía que no le podía pedir eso a su marido a menos que hubiera alguna razón médica por la cual ningún otro método fuera admisible. De no ser así la mujer estaba segura que su esposo interpretaría el pedido de usar condones como una falta de confianza, y que se negaría a usarlos. Es más, siendo la madre de ocho hijos, la mujer no estaba dispuesta a confiar exclusivamente en el condón, porque temía quedar embarazada otra vez. Por lo dicho su objetivo principal era protegerse contra el embarazo.
La mujer y la consejera finalmente decidieron que la mejor opción era colocarse un DIU, pero también decidieron decirle al esposo que el doctor había prohibido el DIU por razones médicas, por lo cual tendrían que usar condones. Así, la mujer podría usar dos métodos simultáneamente para protegerse tanto contra la enfermedad como el embarazo, sin perjudicar la relación con su esposo.

Obviamente, en este caso es importante preguntar si la consejera está fallando en su deber de promover la mejor comunicación posible entre la mujer y su pareja. Aunque la comunicación abierta entre parejas es una meta loable, los proveedores deben medir los beneficios de una mejora en la comunicación contra la necesidad del cliente de protegerse a toda costa. El personal de las APF debe resolver este tipo de dilemas a diario. En este caso, la consejera reconoció que aunque muchos hombres en América Latina apoyan la idea de prevenir embarazos, a la misma vez muchos se sienten amenazados, acusados o traicionados cuando se les pide participar en la prevención de enfermedades. Algunos hombres interpretan el pedido de usar condones como un indicio de que la mujer sospecha que la están engañando o, peor aún, de que ella lo está engañando a él. Esta hipocresía es lamentablemente común en culturas donde la promiscuidad masculina se considera normal y las mujeres suelen ser la parte monógama de una relación.

Un miembro del personal de BEMFAM/ Brasil relató la historia de una mujer que asistió a tres reuniones del grupo femenino de discusión organizado por la APF. Durante la primera sesión, la mujer parecía estar nerviosa pero se quedó callada. Durante la segunda sesión, la mujer hizo varias preguntas sobre síntomas asociados con el SIDA, con evidente emoción. Posteriormente la mujer solicitó consejería individual y durante la reunión con la consejera indicó que temía estar infectada con SIDA. Dijo que pocos días atrás su marido le había confesado que la engañaba, y que desde entonces ella había estado sudando mucho de noche, tenía diarrea y estaba perdiendo peso. También pidió que se le hiciera una prueba para el VIH.

Al regresar a la clínica 15 días más tarde, la mujer se mostró muy aliviada al saber que los resultados habían sido negativos. Durante la tercera y última sesión del grupo femenino de discusión a la que asistió, la mujer dijo que todavía no había podido enfrentar a su marido sobre el tema de usar condones, a pesar del susto que había pasado. "Yo 
sé que es necesario, pero no me animo a pedirle que use el condón. Es mi marido, y si me confesó el engaño, por lo menos es honesto". Después de conversar con la mujer una vez más sobre temas de autoestima, la consejera indicó que se sentía completamente frustrada ante la actitud de la mujer: "La pasividad femenina es algo tan interiorizado que supera el temor a la muerte".

\section{Dinámicas de grupo}

Dado que siempre surgen límites en lo que se puede lograr en una sesión individual, los asesores de BEMFAM/Brasil han encontrado que pequeñas sesiones en grupo como las del ejemplo anterior ofrecen un medio eficaz para nutrir capacidades de comunicación y negociación. Formados como parte de un "Proyecto de Mujeres" en BEMFAM, estos pequeños grupos de discusión (a los que de vez en cuando también asisten hombres) ofrecen un ambiente protegido e informal en el que las mujeres pueden expresar sus inquietudes, apoyarse mutuamente, y aprender nuevas técnicas de comunicación. BEMFAM considera que estas sesiones funcionan de manera complementaria a la consejería individual, y las APF en Honduras y Jamaica han empezado a elaborar sus propios programas de intervención en grupos, tanto para comunidades como para las clínicas, en base al ejemplo brasileño.
Antes de recibir servicios médicos, toclas las mujeres que acuden a clínicas de BEMFAM/Brasil en varias localidades son invitadas a participar en discusiones en pequeños grupos dirigidos por una facilitadora especialmente entrenada. Las participantes leen y discuten el contenido de breves novelas ilustradas que contienen historias sobre la vida real de mujeres contemporáneas. Las "novelas" tratan temas como el VIH y las ETS, la percepción del riesgo, y la comunicación en pareja, y la facilitadora las usa para entablar discusiones más amplias sobre salud, sexualidad y relaciones interpersonales.

Al compartir estas historias de la vida las mujeres se dan cuenta que no están solas en su manera de sentir. La situación de grupo permite que las participantes se exterioricen y que hagan valer sus opiniones en un ambiente seguro; esto les ayuda a superar la intimidación que suelen sentir cuando tratan de hablar con sus parejas sobre sexualidad o sobre prácticas preventivas.

\section{- Rita Badiani}

Hay varios ejemplos de cambios positivos en la vida de mujeres que participaron en estas discusiones de grupo. Una mujer participó en dos sesiones donde dijo que le gustaría encontrar un empleo para no depender tanto de su pareja. Cuando vino por tercera vez la mujer orgullosamente le contó al

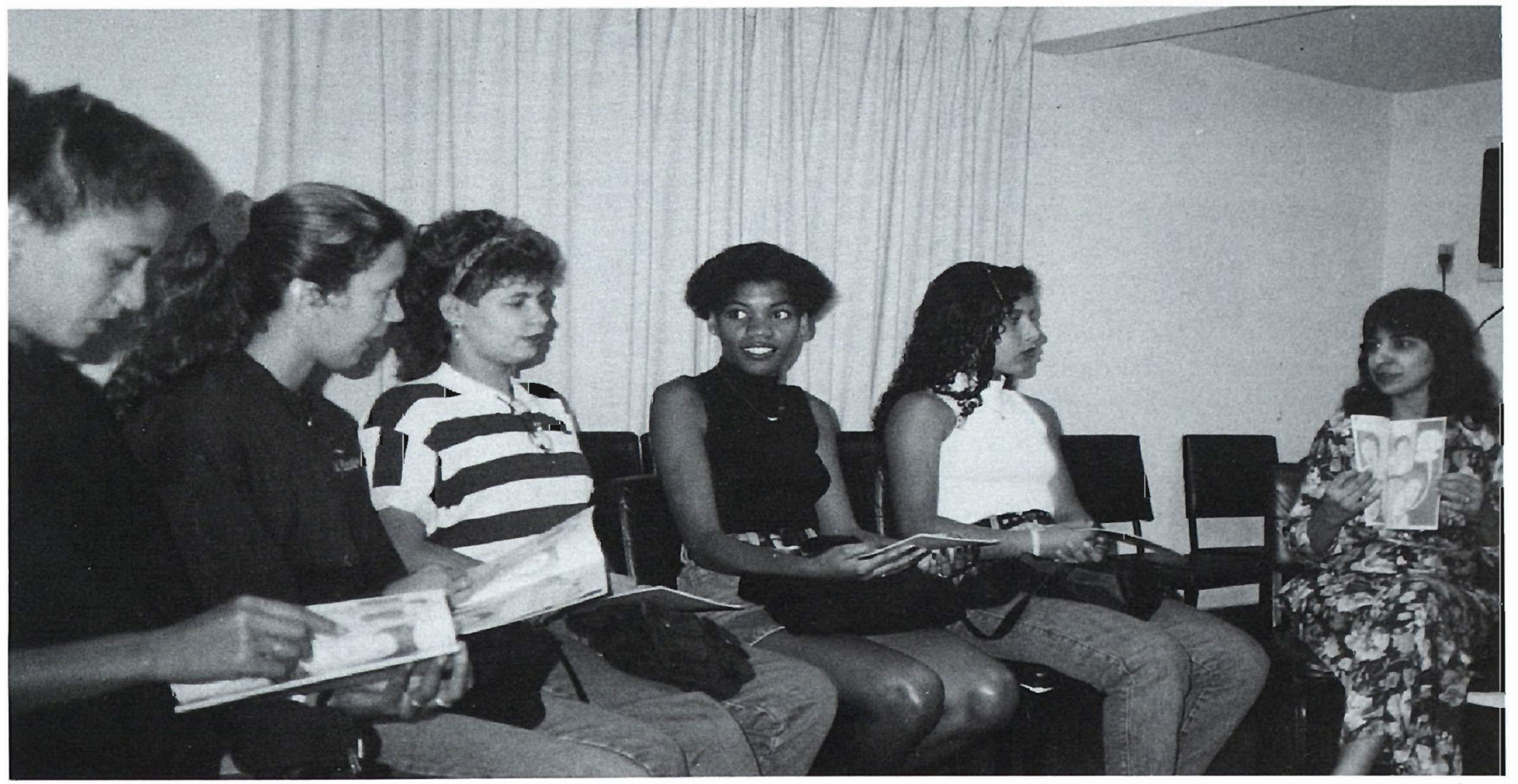


grupo que había encontrado un trabajo. Otra mujer que participó en tres sesiones habló de cómo había logrado que su marido usara condones:

Después de pelearnos varias veces, logré que mi marido usara el condón. Primero tuve gritarle y llorarle. Le dije que su pene quedaba más grueso y me daba más placer [con el condón puesto]. Ahora hace tres meses que los está usando. Yo me siento más segura y verdaderamente siento más placer.

Además de ayudar a que los clientes exterioricen sus inquietudes, las actividades de grupo, ya sean formales o informales, suelen sacar al aire necesidades e intereses de los clientes que cle otro modo podrían permanecer ocultos. Por ejemplo, luego de una discusión inicial sobre el VIH, las ETS y la planificación familiar entre mujeres en la sala de espera de una APF en Jamaica, la conversación repentinamente cambió rumbo hacia el tema del abuso sexual en las comunidades locales. Aunque estas mujeres querían saber más sobre el riesgo de contraer el VIH, quedó claro que lo que más les preocupaba era el abuso sexual (y los riesgos generales asociados con dicho abuso, incluso la transmisión del VIH).

\section{CONSECUENCIAS INSTITUCIONALES}

Para emprender un programa innovador como este hizo falta mucho más que simplemente capacitar al personal para que adoptara nuevas técnicas. También fue necesario que las APF implementaran cambios al nivel institucional, reorganizando las estructuras de administración y los esquemas para la asignación de puestos en el personal.

\section{Compromiso}

Los coordinadores del proyecto en cada una de las tres APF hicieron hincapié en el hecho de que para tener éxito es fundamental conseguir un compromiso institucional explícito y un reconocimiento del papel que el programa va a tener dentro de la misión general de la APF. Según Rita Badiani de BEMFAM/Brasil, si la misión de una APF consiste en "proveer servicios de salud sexual y reproductiva de alta calidad", entonces todos los programas y servicios-incluso los de prevención y tratamiento del VIH y las ETS-deben contribuir a lograr ese objetivo mayor. Es decir, la filosofía del programa innovador debe encajarse en las metas generales de la institución. El director eje- cutivo de FAMPLAN/Jamaica dijo lo siguiente al respecto:

Teniendo en cuenta la resistencia que siempre surge cuando se trata de cambiar métodos y conceptos antiguos, queda claro que es importante manejar bien el cambio. El apoyo de los más altos niveles de la gerencia debe ser muy concreto y muy visible desde el principio, y este compromiso se debe extender a todo el personal, especialmente aquellos que están implementando el proyecto. El personal debe participar en cada etapa del proceso, desde la planificación del programa hasta su implementación y evaluación.

\section{-Peggy Scott}

\section{Temas estructurales}

Las APF han descubierto que la ubicación de este tipo de proyecto dentro de la estructura de la organización puede determinar la manera en que la filosofía del proyecto se arraiga en la institución. En ASHONPLAFA/Honduras, por ejemplo, el programa inicialmente fue colocado bajo la responsabilidad exclusiva de un empleado nuevo quien fue contratado para ese propósito. Como resultado, los otros miembros del personal concluyeron que el programa era un esfuerzo aislado en el que no iban a tener parte. Un gerente de programas lo explicó así:

Cuando nombraron a la nueva coordinadora para un proyecto sobre educación y asesoramiento, los miembros del personal pusieron resistencia porque no les gustó que otra persona estuviera recibiendo sueldo. Todos pensaban: "Esto es responsabilidad de la nueva. Yo ya tengo mi trabajo bien definido. Que se encargue ella de trabajar en [prevención del VIH y las ETS]". Fue dificil motivar a la gente y ayudarle a comprender que el proyecto le pertenecía a toda la APF y no sólo a una persona o un departamento. Fue un proceso largo y duro... pero finalmente todos decidieron apoyar al proyecto... Ahora estoy convencida que el personal se ha identificado con el proyecto y que lo ven como parte de la institución.

\section{- Maria Roberta Bulnes}

En Honduras, el éxito del programa se debió en gran medida a jóvenes miembros del personal que se organizaron en base a un intenso compromiso personal con la prevención y el trata- 
miento del VIH y las ETS. Estos jóvenes se convirtieron en catalizadores para que la gerencia de ASHONPLAFA se comprometiera también. En BEMFAM/Brasil, por otro lado, la responsabilidad por la nueva iniciativa fue colocada desde el principio en manos de gerentes superiores con mucha antigüedad en la institución, por lo cual fue fácil implementar el programa y generar el apoyo de todo el personal.

A pesar de estas diferencias administrativas, los gerentes de programas en cada una de las tres APF encontraron que el nuevo proyecto en algunos casos chocó con las líneas de autoridad establecidas. Uno de los desafíos más frecuentes surgió del hecho de que las actividades del programa son multidisciplinarias e involucran a varios departamentos dentro de la institución. Esto ocasionó momentos de confusión en cuanto a la supervisión del programa, dado que esta función quedaba dentro de un departamento, mientras que varios otros debían participar en la implementación.

\section{LOGROS DEL PROGRAMA}

\section{Cambios observados}

Como se aprecia en los ejemplos anteriores, el modo de entrega de los servicios en cada una de las tres APF cambió profundamente en los tres o cuatro años que funcionó el programa. Algunos cambios positivos se manifestaron inmediatamente después de los primeros talleres de capacitación, los cuales duraban tres o cuatro días cada uno. Pero el personal necesitó mucho más tiempo para refinar las capacidades aprendidas durante los talleres, para familiarizarse a fondo con los nuevos temas, y para aprender a integrar las prácticas resultantes dentro de los límites del entorno clínico. Por ejemplo, muchas consejeras inicialmente reemplazaron el enfoque anterior en la entrega de información sobre anticonceptivos con el nuevo enfoque en información y consejos sobre el VIH y las ETS. Luego empezaron a pedir información sobre riesgos, y poco a poco, impulsados por comentarios de los clientes mismos, dichas consejeras llegaron a sentirse cómodos con la técnica del diálogo recíproco para explorar la situación del cliente. La institucionalización de estos conceptos también resultó ser un proceso de largo plazo, dado que involucró un cambio permanente en el modo de entrega de los servicios de planificación familiar. A lo largo del proyecto, el personal de las tres APF no dejó de recibir c‘apacitación y comentarios de colegas, supervisores y la IPPF NHHR. Es preciso establecer un mecanismo para asegurar que el personal siga recibiendo capacitación y apoyo ahora que se ha acabado el financiamiento inicial.

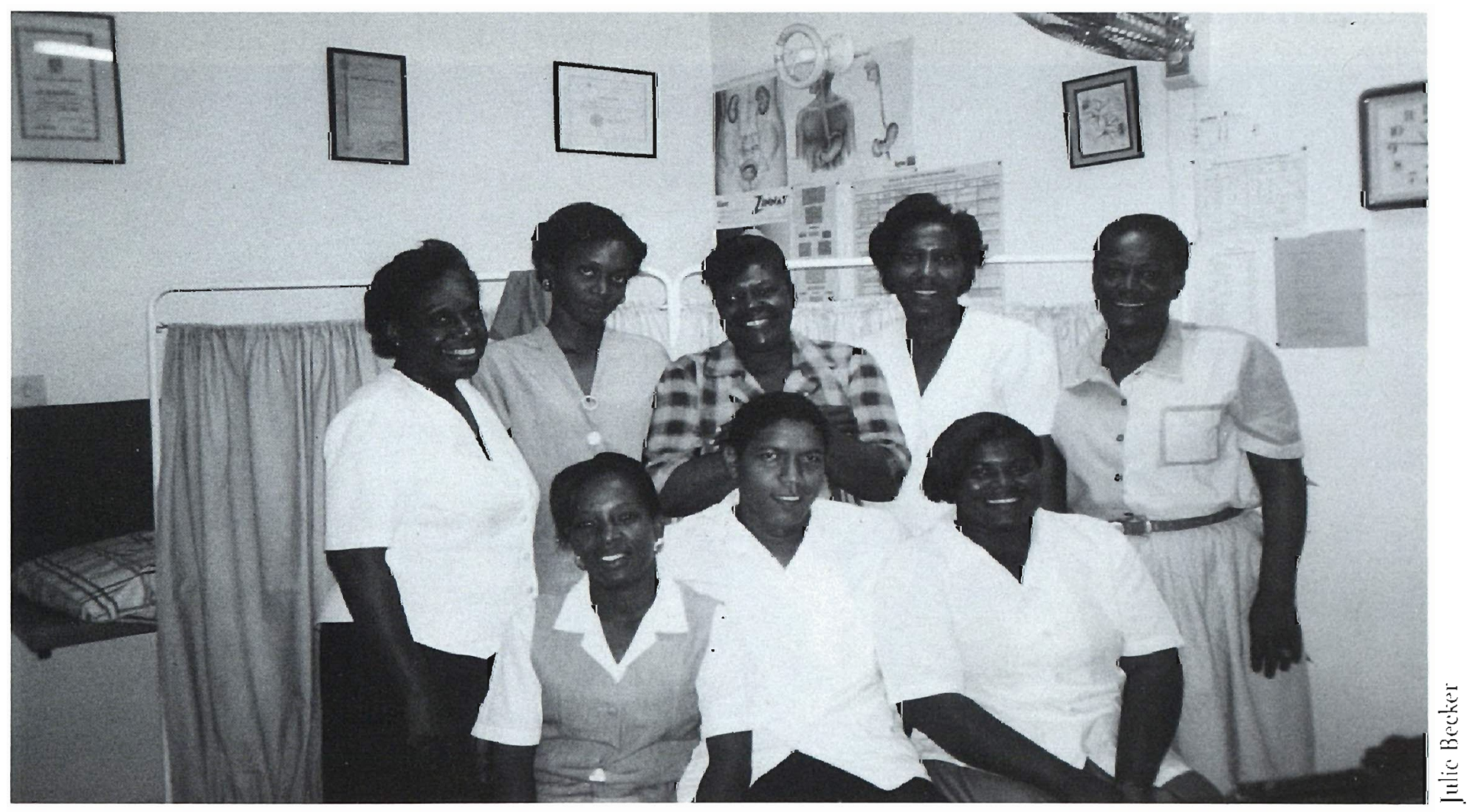




\section{Mejoras en la calidad de los servicios de planificación familiar}

Sin duda el cambio más notable producido por el programa fue el aumento en la utilización de condones. Aunque el número de condones distribuidos creció de manera impresionante durante el primer año del proyecto, varios otros factores de disponibilidad y acceso a condones hicieron que este número cayera en los años posteriores. A pesar de eso el personal informa que los clientes piden cada vez más condones. En Jamaica y Honduras se le ofrecen condones gratuitos a todos los clientes nuevos, y el personal indica que el $90 \%$ de los clientes los aceptan. Algunos clientes dicen que ponen condones en las maletas y los cajones de sus parejas, o que se los están dando a sus hijos adolescentes. En Brasil, el 36\% de los clientes que adoptan un método de planificación familiar por primera vez ahora elige el condón, y $5 \%$ opta por usar el condón con otro método. Las mujeres que participan en discusiones de grupo reciben condones gratuitos y pueden pedir más cuando regresan.

\section{Efectos en la vida privada de los miembros del personal}

Algunos trabajadores en las APF dijeron que su experiencia con el programa les ayudó personalmente, especialmente en cuanto a la comuni- cación con sus familias. Como explicó un empleado en Brasil: "Encuentro que he llegado a ser una persona mejor, no sólo un mejor empleado de BEMFAM. En algunos casos hasta han mejorado mis conversaciones en casa". Los gerentes del programa en Brasil y Honduras dijeron además que sus empleados piden cada vez más condones para uso personal.

Un médico de BEMFAM/Brasil habló de cómo había podido relacionar su trabajo con su vida personal:

La capacitación sin duda contribuyó a mejorar mi vida profesional, pero también me ayudó en lo personal, como persona que ama, vive, sufre, goza. Porque la verdad es que el trabajo es como una escuela en relaciones humanas. Uno aplica lo que aprende [al trabajar con clientes] a su relación con el padre, la madre, la esposa, los hijos, quien sea con que uno se relaciona... uno puede extrapolar lo que aprende porque el cliente es un ser humano.

-Dr. Roberto Dias Fountes

\section{OBSTACULOS AL CAMBIO}

Los cambios en el comportamiento del personal propuestos por este programa no siempre fueron fáciles de realizar, y cada miembro del personal demostró distintos niveles de interés y apertura.

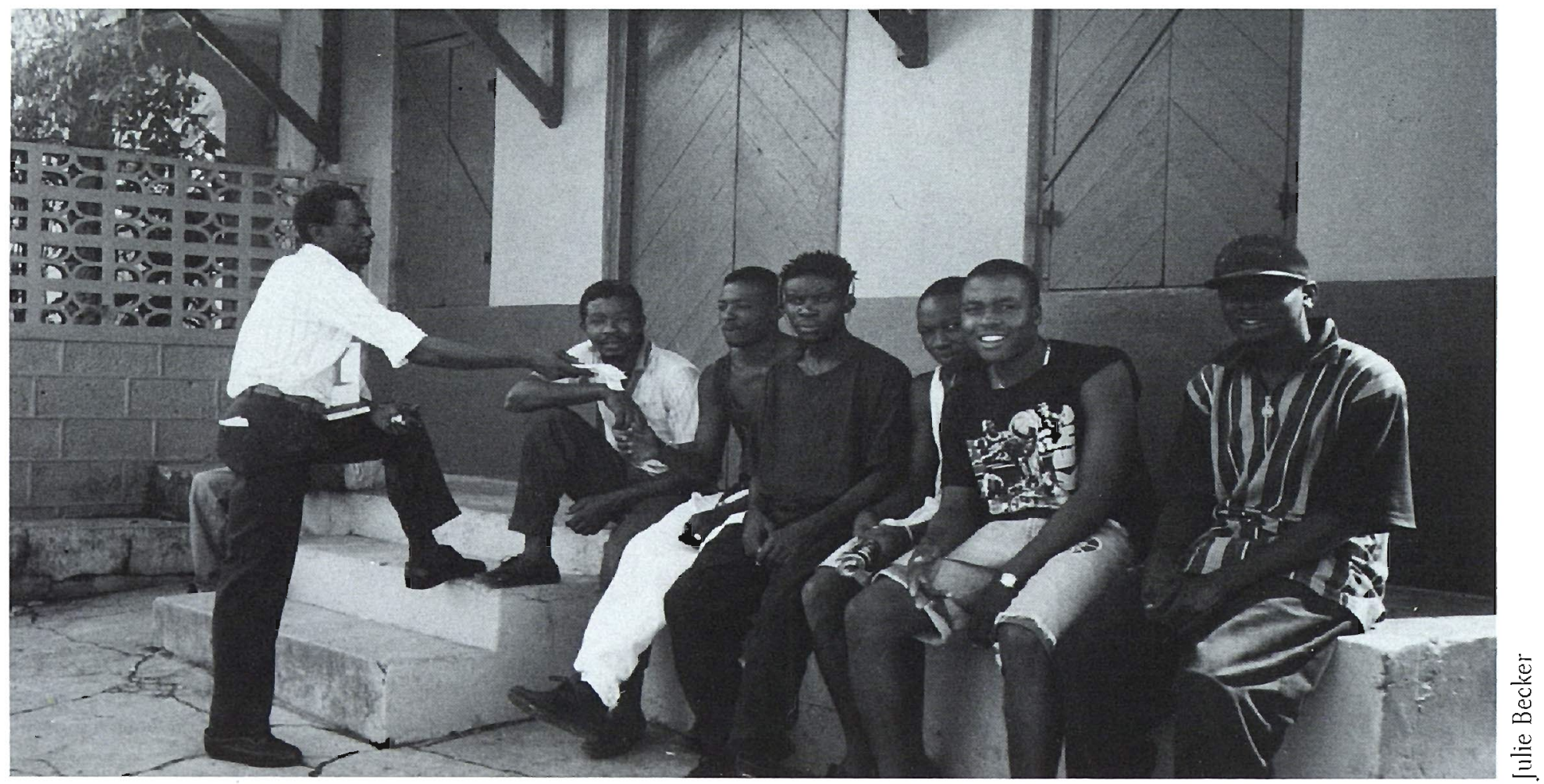




\section{Resistencia del personal}

Algunos miembros del personal, especialmente aquellos que habían trabajado de una manera particular durante muchos años, al principio se resistieron al cambio y se mostraron reacios a alterar sus métodos y responsabilidades. Peggy Scott de FAMPLAN/Jamaica enfatizó que esto no le sorprendió a nadie: "Cualquier cambio en el ambiente de trabajo inevitablemente causa cierta cantidad cle tensión, y así fue". Algunos trabajadores no se sentían cómodos tratando temas sexuales de modo tan directo. Por ejemplo, en BEMFAM/ Brasil, algunas de las doctoras al principio se resistieron a realizar exámenes para ETS en pacientes masculinos. El director médico de BEMFAM/Brasil describió así la situación:

A los esposos de las doctoras no les gustaba la idea de que ellas atendieran a hombres y les tocaran el pene... Hoy las doctoras realizan exámenes sin el menor problema. Sólo una doctora se ha negado a hacerlo debido a la oposición de su esposo.

\section{-Dr. Ney Costa}

\section{¿Más trabajo?}

$\mathrm{Al}$ principio algunos miembros del personal en cada una de las APF querían saber si el programa produciría más responsabilidades de trabajo sin un aumento proporcional en la compensación. De acuerdo con Joan Black de FAMPLAN/Jamaica, resultó difícil superar esta percepción: "El personal manifestó reacciones variadas... Algunos dijeron que necesitaban un aumento porque estaban trabajando más... pensaban que [las nuevas actividades] los dejaban más agotados, por lo cual se les debía compensar más". Estas percepciones sólo empezaron a disminuir cuando el personal comprendió que en vez de realizar más actividades se les estaba pidiendo que cambiaran su manera de hacer las tareas que ya llevaban a cabo. En Jamaica, las descripciones formales del trabajo de cada empleado simplemente fueron modificadas en el momento de su evaluación anual.

\section{¿Falta de tiempo?}

Debido a la gran cantidad de clientes que solicitan servicios, el personal de las APF suele tener poco tiempo de sobra y siempre está consciente de los clientes en la sala de espera. Inicialmente algunos trabajadores temían que los nuevos méto- dos requerirían más tiempo y causarían más demoras en la atención. Pero poco a poco encontraron que con la práctica las nucvas actividades no necesariamente resultan en consultas más largas. Al empezar la consulta con preguntas sobre las circunstancias particulares del cliente, los asesores logran ajustar la sesión a las necesidades específicas del individuo, eliminando información ajena que antes hubieran incluido. En realidad muchos asesores encuentran que se puede ahorrar tiempo al enfocar la sesión en las necesidades particulares de cada cliente. En Brasil, las sesiones en grupo también resultaron en una utilización más económica y eficaz del tiempo del personal.

\section{FACTORES QUE FACILITARON EL CAMBIO}

Aunque la capacitación contribuyó materialmente al cambio en las prácticas y actitudes del personal de las APF, también influyeron otros factores. Durante el proceso paulatino de reconceptualización y redefinición de cargos en base al nuevo enfoque propuesto por el programa, el personal identificó varios agentes de cambio específicos.

\section{La evolución en la naturaleza de la epidemia del SIDA}

A medida que más y más gente fue quedando afectada directa o indirectamente por el VIH/SIDA, el personal modificó sus percepciones sobre quiénes corren riesgo de quedar enfermos. Los proveedores ahora ven que la situación les afecta "en casa propia" (es decir, que los clientes tradicionales de planificación familiar también están en situación de riesgo), y reconocen la importancia de atender al tema dentro de sus prácticas profesionales.

Al principio se pensaba que el VIH/SIDA era una enfermedad de homosexuales que luego se convirtió en una enfermedad de gente inmoral o de prostitutas. Se creía que los heterosexuales no corrian peligro, especialmente si estaban casados o en relaciones estables. Pero al ver el aumento en la canticlad de gente que estaba quedando enferma, la APF decidió que debia participar en los esfuer os de prevención.

-Peggy Scott

Un sentido de compromiso personal

En cierto sentido el SIDA en sí, al ser una 
amenaza concreta contra la cual la gente se podía organizar, sirvió para motivar al personal de las APF. En efecto, el SIDA funcionó como un catalizador para llegar a una mejor comprensión de las ventajas de trabajar dentro de un marco más amplio de sexualidad y salud sexual. El SIDA provocó una profunda preocupación entre el personal, obligándolos a tomar responsabilidad por la protección de sus clientes y sus comunidades. Como explicó un supervisor de promoción de ASHONPLAFA/Hondinras: "Yo cambié de perspectiva. Vi gente que estaba luchando por no perder la vida, y ahora siento una obligación moral de enseñarles a los otros cómo se pueden proteger". Y una consejera de ASHONPLAFA dijo lo siguiente:

Lo que me ha motivado a mi es el hecho de que este es un trabajo social hermoso. Porque se trata de salvar una vida humana. Esto es algo que hago para mi y para mi familia, especialmente mi hija.

-Thesla Bustillo

Muchos miembros del personal de ASHONPLAFA/Honduras dijeron que conocen a alguien que está infectado con el VIH o que murió de SIDA.

\section{La influencia de los colegas}

Los trabajadores en cada una de las APF dijeron que la exitosa adopción del nuevo enfoque se clebió en cierta medida al sentido de solidaridad entre colegas. A medida que veían cómo sus colegas cambiaban de actitud y modificaban sus prácticas, muchos miembros del personal decidían cambiar por su cuenta. En ASHONPLAFA/Honduras, por ejemplo, se crearon "Equipos Motores" que trabajaban con el personal en cada distrito. Estos equipos organizaban concursos en los que los empleados de cada centro creaban pinturas murales, materiales educativos, poesías y cuentos sobre temas de salud sexual, fomentando un sano espíritu de competencia. Un miembro de uno de los "Equipos Motores" dijo que "A medida que adquirimos más experiencia y modificamos la manera en que enfrentamos nuevos temas y problemas, la influencia de nuestros colegas surgió como una importante causa del cambio". Otro dijo: "Nos incitamos a seguir adelante, sobre todo porque no dejamos de apoyarnos mutuamente y de compartir experiencias".

Una discusión con trabajadores de extensión rural de FAMPLAN/Jamaica también indicó que éstos dependían del apoyo de sus colegas. Dichos trabajadores dijeron que sus colegas sirvieron para alentarlos y para introducir nuevas ideas sobre cómo atender mejor a los clientes.

\section{Ofreciendo nuevos desafios profesionales}

Los rigores del programa también proporcionaron nuevos desafíos profesionales para el personal. Al asumir nuevas responsabilidades, muchos decidieron que necesitaban extender su capacitación profesional. Muchos otros hablaron de un nuevo nivel de satisfacción en el trabajo gracias a sus nuevos roles. Un empleado dijo que "Para mí, este [proyecto] ha sido una gran ayuda. Uno puede ver los resultados, y esto me causa satisfacción como empleado, como asesor y como persona”.

Los dirigentes de ASHONPLAFA/Honduras y FAMPLAN/Jamaica encontraron que al involucrar al personal de apoyo en las actividades de educación y consejería lograban darles un sentido de reconocimiento que mejoró la moral de trabajo y la calidad de atención a los clientes. Por ejemplo, las recepcionistas y los choferes de FAMPLAN/Jamaica mostraron mucho entusiasmo por las discusiones informales que se les alentó a entablar con los clientes en la sala de espera. En ASHONPLAFA/Honduras, miembros del personal desde la citologista hasta los choferes y las secretarias empezaron a participar en las actividades educativas y de consejería. Cuando la citologista no está ocupada en el laboratorio con pruebas de Papanicolao, suele salir a la sala de espera para conversar informalmente con los clientes. Los choferes han formado su propia organización para iniciar conversaciones con clientes en salas de espera o en sus propias comunidades. Y las secretarias han participado en manifestaciones para concientización pública, como ser ferias cle salud y las actividades del Día Mundial del SIDA.

\section{Lecciones aprendidas}

1. No se puede exagerar la importancia de un compromiso institucional con la atención a las necesidades sexuales de los clientes. Para asegurar que la institución se comprometa con una innovación tan controversial como la atención a la sexualidad de los clientes, es indispensable colocar responsabilidad sobre el tema en manos de los gerentes superiores de la APF. Porque a menos que los niveles más altos de la institución estén dispuestos a comprometerse, y a inver- 
tir el tiempo y los recursos necesarios, una innovación tan trascendente jamás se podrá arraigar. Es más, la gerencia debe cultivar un ambiente en el que los demás miembros del personal puedan explorar de modo honesto sus propias actitudes hacia un tema tan íntimo, y deben apoyarlos durante la difícil transición a un nueva relación con los clientes que encuentran a diario.

2. La inclusión de todos los niveles del personal en la planificación, implementación y seguimiento de discusiones sobre sexualidad con los clientes, hace que todos los trabajadores se sientan "dueños" de las nuevas prácticas. Todos los miembros del personal de la APF, incluso aquellos que tradicionalmente no tienen responsabilidades directas en cuanto a la educación de clientes, aprecian la oportunidad de participar en estas actividades, dado que les permite sentir que contribuyen a realizar las metas de la organización. Por ejemplo, en Honduras todos, desde el chofer hasta la citologista, participan en algún aspecto de la consejería y la educación; en Jamaica las recepcionistas y los choferes dicen que les satisface mucho el tener discusiones informales con clientes en la sala de espera.

3. La capacitación, aunque es fundamental, no es suficiente como para cambiar de por sí las actitudes del personal sobre la sexualidad de los clientes, o para hacer que estén más dispuestos a discutir cuestiones íntimas con los clientes. Como el Dr. Fathalla correctamente observa en la introducción a este informe, "Es mucho más fácil impartir nuevos conocimientos a los proveedores de servicios o ayudarles a conseguir nuevas capacidades técnicas. El gran desafío consiste en cambiar la actitud de los proveedores hacia la sexualidad..." Las actitudes nunca cambian de modo instantáneo; lo hacen más bien como parte de un proceso. Para que ese proceso funcione, los proveedores necesitan el apoyo de sus superiores y muchas oportunidades para compartir experiencias con sus colegas.

4. Aunque muchos suponen que conversar sobre sexualidad con el cliente consume demasiado tiempo, en realidad estas discusiones suelen ahorrarle tiempo al asesor. Esto se debe al hecho de que dichas conversaciones "abren la puerta" y permiten que el cliente exteriorice sus necesidades más urgentes, lo cual ayuda a que la consejera identifique de inmediato la información o el comportamiento que el cliente necesita comprender. En muchos casos esto permite que la sesión sea más breve y eficaz, comparada con sesio- nes tradicionales en las que la consejera recitaba una lista de todos los métodos y servicios disponibles sin consideración de las necesidades específicas del cliente.

5. La consejería integrada adaptada a las necesidades del individuo (a un cliente por turno) suele mejorar la calidad del servicio, al mismo tiempo que mejora el sentido de satisfacción profesional del proveedor. LoS miembros del personal que participaron en estos tres proyectos dijeron que se sienten más satisfechos con su trabajo desde que empezaron a incluir discusiones sobre sexualidad con cada cliente. Dijeron que ahora sienten que están teniendo un efecto concreto en la vida de la gente. Muchos proveedores también afirmaron que algunos de los cambios positivos del programa los afectaron personalmente, ayudándoles a ser más sensibles y compasivos.

6. Al contrario de lo que se suele suponer, no es difícil lograr que los clientes hablen francamente sobre sus vidas sexuales. Es más, muchos hombres y muchas mujeres se muestran aliviados culando por fin pueden conversar con alguien sobre estos temas. Resulta alentador descubrir que uno no es el único que enfrenta problemas como la posibilidad de quedar infectado, la falta de satisfacción sexual, o la infidelidad. Estas reacciones positivas han servido para motivar a los proveedores a seguir perfeccionando este nuevo estilo de diálogo con el cliente.

7. No sólo los individuos están dispuestos a conversar abiertamente sobre su vida sexual. La discusión de temas sexuales en grupos también resultó muy aceptable-especialmente para mujeres. Muchas mujeres respondieron con entusiasmo a la oportunidad de discutir sexualidad, desigualdades de género y las relaciones del poder en un foro dirigido por una facilitadora capaz de contestar preguntas y proveer información sobre fuentes de apoyo y dirección en sus propias comunidades. En algunas de las localidades de BEMFAM/Brasil, todas las mujeres que vienen a la clínica son invitadas a participar en un grupo de discusión. Estos grupos no sólo permiten que las mujeres compartan experiencias en un ambiente seguro, sino que también facilitan el aprendizaje de técnicas de asertividad y comunicación que pueden usar con sus parejas.

8. La prestación de servicios de planificación familiar enfocados en la sexualidad ha resultado en un importante aumento en el uso de condones. Antes de este proyecto, los condo- 
nes casi nunca eran promovidos como métodos anticonceptivos en estas tres APF, o sólo se recomendaban como "respaldo" para otros métodos. En la actualidad los condones son una de las principales opciones anticonceptivas, y el nivel de uso ha aumentado tanto entre los clientes como entre el personal. Mientras que anteriormente muchos de los proveedores no podrían haber demostrado el uso correcto del condón, hoy se apresuran a hacerlo mediante un modelo de pene. Por lo dicho los clientes ya no se van de la clínica con sólo un paquete cerrado, sino que saben cómo colocar un condón y cómo desecharlo una vez usado. Los asesores también se aseguran de que los clientes comprendan el nivel de eficacia del condón en la prevención del embarazo y la protección contra las ETS, y que sepan qué tácticas se pueden usar para negociar el uso del condón con una pareja que se resiste. En varias clínicas también se ha visto un aumento en el número de clientes que han decidido usar dos métodos (condones mas otro anticonceptivo) en base a su propia evaluación de sus necesidades en situaciones particulares.

En resumen, los gerentes y el personal de estas tres APF sienten que están logrando un cambio positivo en el modo de entrega de sus servicios a medida que enfatizan las necesidades y las circunstancias sexuales de los clientes. Este enfoque ha tenido un profundo impacto en la calidad de los servicios.

\section{Notas}

1. Banco Mundial, 1993. World Development Report: Investing in Health. New York: Oxford University Press.

2. Los fondos fueron provistos mediante un suplemento del proyecto de la Oficina de Salud del USAID que fue dirigido al Proyecto de Transición financiado por la Oficina de Población de la USAID.

3. Las citas basades en entrevistas en español fueron traducidas al inglés durante la redacción de este informe. La traducción posterior del informe entero al español puede haber alterado algunas de la citas originales.

\section{Reconocimientos}

Quisiéramos agradecer a todo el personal de BEMFAM/Brasil, ASHONPLAFA/Honduras, y FAMPLAN/Tamaica, y especialmente a los que participaron en las discusiones, entrevistas y grupos de enfoque que formaron la base para este informe.

BEMFAM: Rita Badiani y Ney Costa, coordinadoras del proyecto. Maria José Sabino, Angela Maria Dantas, Jane Nunes, Maria de Fátima Oliveira, Gilson Oliveira, Edilma Costa, Francisca Moura, Luciene Octacílio, Virginia Andrade. El grupo de enfoque fue conducido por Katia Moura, Maria do Socorro Silva, Catarina M. Da Silva, Vania Bastos Petti, Cleusa Souza dos Santos, Elizabeth Afonso, Maria Luiza da Silva, Roberto Dias Fountes, Dilmara da Cruz Andrade, Jussara Rocha, Gilda Maria Dutra, Lucia Maria Costa, Josenilda de Carvalho, Katia Mora. Las entrevistas fueron conducidas por Maria Regina Oliveira y Sonia Dantas.

ASHONPLAFA: María Elena de Pérez y María Roberta Bulnes, coordinadoras del proyecto. Gloria Flores, Thesla Bustillo, Yolanda Ruiz. Las entrevistas fueron conducidas por Julie Becker.

FAMPLAN: Dunneth Willocks, Una Watson, Larnes Small, Beverly Ringrose, Melrose Jones, Carmen McKenzie, Lilieth Richards, Marcia Broderick, Beverly Lambert, Yvonne Woodbine, Pauline Pennant. El grupo de enfoque fue conclucido por Maricela Ureño y Pauline Pennant.

También quisiéramos reconocer a las siguientes personas por su valiosa contribución a la preparación de este proyecto: Maricela Ureño, Claudia Mora, Judith Helzner, Ann Denise Brown, Elizabeth Kirberger, Doris Bertzeletos y Niclıolas Frost. 


\section{Sobre las Autores}

Julie Becker conduce el Programa de Prevención del VIH/SIDA de la Federación Internacional de Planificación de la Familia, Región clel Hemisferio Occidental (IPPF/RHO). Su trabajo en salud pública, tanto en el ámbito local como en el internacional, se ha enfocado principalmente en sexualidad, salud sexual $y$ reproductiva, y prevención del VIH/SIDA.

En el momento en que se redactó este artículo, Elizabeth Leitman trabajaba como consultora independiente internacional en salud reproductiva de la mujer: En la actualidad Leitman funciona como oficial asistente de programas para América Latina en la International Women's Health Coalition.

Mahmoud Fathalla es director asociado de la división de Ciencias cle Población de la Fundación Rockefeller y profesor de obstetricia y ginecología de la Universidad de Assuit, en Egipto.

\section{Comité asesor de Quality/Calidad/Qualité}

\author{
Ian Askew \\ Karen Beattie \\ Martlua Brady \\ George Brown \\ Judith Bruce \\ Christa Coggins \\ Adrienne Germain \\ Joan Haffey \\ Nicole Haberland \\ Judith Helzner \\ Ann Leonard \\ Magaly Marques \\ Elizabeth McGrory \\ Kirsten Moore
}

\author{
Nancy Newton \\ John Paxman \\ Geeta Rao Gupta \\ Julie Reich \\ Debbie Rogow \\ jill Sheffield \\ Cynthia Steele Verme \\ Karen Stein \\ Kerstin Trone \\ Nalind Toubia \\ Gilberte Vansintejan \\ Beverly Winikoff \\ Margot Zimmerman
}

$\begin{array}{ll}\text { Diseño: } & \text { Ann Leonard } \\ \text { Fotos de tapa: } & \text { ASHONPLAFA/Honduras, } \\ & \text { Julie Becker, Adriane Martin-Hilber, } \\ & \text { Maricela Ureno } \\ \text { Tipografía: } & \text { Heidi Neurauter } \\ \text { Impresión: } & \text { Graphic Impressions } \\ \text { Traducción: } & \text { Paul Constance }\end{array}$

Diseño:

Fotos de tapa:

Anll Leonald

ASHONPLAFA/Honduras,

Julie Becker, Adriane Martin-Hilber,

Heidi Neurauter

Paul Constance

Solicitamos sus comentarios e ideas sobre proyectos que podrían ser incluidos en futuras ediciones de Quality/Calidad/Qualité. Si desea recibir ejemplares adicionales de esta edición o quisiera ser incluido en nuestra lista postal, favor de escribir a: Ann Leonard, Editor, Quality/Calidad/Qualité, Population Council, One Dag Hammarskjold Plaza, New York, NY 1.0017 U.S.A. 


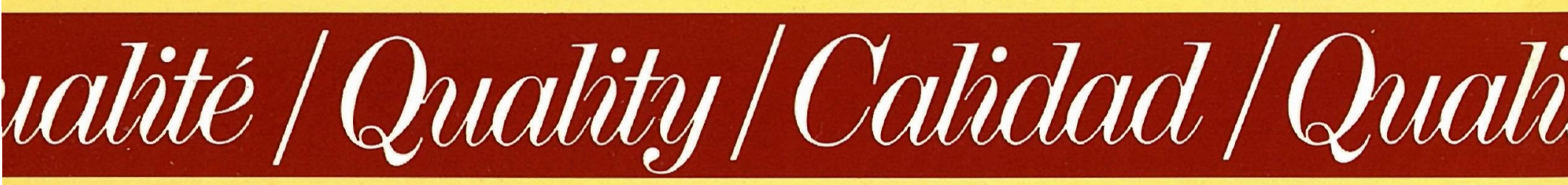

